\title{
Recent Advances in Immobilization Strategies for Biomolecules in Sensors Using Organic Field-Effect Transistors
}

\author{
$\mathrm{Le} \mathrm{Li}^{1}$ · Siying Wang ${ }^{1} \cdot$ Yin Xiao $^{2} \cdot$ Yong Wang $^{1}$
}

Received: 28 October 2019 / Revised: 13 December 2019 / Accepted: 17 December 2019 / Published online: 27 January 2020

(C) The Author(s) 2020

\begin{abstract}
Organic field-effect transistors (OFETs) are fabricated using organic semiconductors (OSCs) as the active layer in the form of thin films. Due to its advantages of high sensitivity, low cost, compact integration, flexibility, and printability, OFETs have been used extensively in the sensing area. For analysis platforms, the construction of sensing layers is a key element for their efficient detection capability. The strategy used to immobilize biomolecules in these devices is especially important for ensuring that the sensing functions of the OFET are effective. Generally, analysis platforms are developed by modifying the gate/electrolyte or OSC/electrolyte interface using biomolecules, such as enzymes, antibodies, or deoxyribonucleic acid (DNA) to ensure high selectivity. To provide better or more convenient biological immobilization methods for researchers in this field and thereby improve detection sensitivity, this review summarizes recent developments in the immobilization strategies used for biological macromolecules in OFETs, including cross-linking, physical adsorption, embedding, and chemical covalent binding. The influences of biomolecules on device performance are also discussed.
\end{abstract}

Keywords Organic field-effect transistor $\cdot$ Biosensor $\cdot$ Biomolecular immobilization strategy $\cdot$ Device performance

\section{Introduction}

As a type of voltage-controlled active device, the organic field-effect transistor (OFET) consists of a source, drain, gate, and organic semiconductor (OSC) and dielectric layers. In the working principle of the typical OFET, carriers are induced by applying gate voltage to form conductive channels at the interface between the OSC and dielectric layers. The charges in the conductive channel are injected by the source electrode and collected by the drain electrode. The width of the conductive channel, i.e., the charge density, can be adjusted by controlling the gate voltage to generate the

Yin Xiao

xiaoyin@tju.edu.cn

$\triangle$ Yong Wang

wangyongtju@tju.edu.cn

1 School of Science, Tianjin Key Laboratory of Molecular Optoelectronic Science, Department of Chemistry, Collaborative Innovation Center of Chemical Science and Engineering, Tianjin University, Tianjin 300072, China

2 School of Chemical Engineering and Technology, Tianjin Engineering Research Center of Functional Fine Chemicals, Tianjin University, Tianjin 300072, China expected current output [1]. Compared with inorganic fieldeffect transistors, the OFET has many unique advantages such as low cost, flexibility [2], and good biocompatibility, and shows promising potential for application in biosensing, wearable devices, and electronic health detection.

OFET biosensors utilize bio-sensitive materials as recognition units that monitor chemical substances or binding events by converting the change in the analyte's concentration or species into electrical signals [3]. The performance of OFET devices can be significantly improved by integrating biomolecules, such as bovine serum albumin (BSA) [4], silk fibroin (SF) [5-8], keratin [9], and streptavidin (SA) [10]. There have been a number of investigations of the use of proteins as a functional interlayer in the OFET [11]. Biotin proteins as functional interlayers can be integrated into OFET devices by spin-coating or layer-by-layer electrostatic deposition [12]. Therefore, the construction of sensing layers is a key factor for establishing OFET recognition systems. Currently, OFET devices have widespread application prospects for analyzing essential components in body fluids related to human health [13, 14], monitoring cell activity [15-17], and identifying neutral chiral ligands [18] and the conformation and dipole moment changes in complex protein-ligand binding processes [19]. Based on the specific 
interactions between analytes and immobilized biomolecules in devices, including enzyme-substrate, antibody-antigen, and DNA-target DNA interactions, OFET sensor platforms can convert a recognition event into an electrical signal. Immobilization strategies for biomolecules play a vital role in the establishment of OFET sensors, because so many factors must be considered, including the optimal biological activity, reducing non-specific adsorption, and maintaining device performance. Hence, a great amount of research attention has been drawn to the targeted, ordered, and controlled immobilization of biomolecules on the sensing layer. In this review, the immobilization strategies of OFET sensors are discussed according to the types of biomolecules employed.

\section{Immobilized Strategies of Enzymes}

The contents of some biological molecules in body fluids can be used as indicators for the early detection of certain diseases. For example, blood sugar is used to diagnose diabetes mellitus, urea content is closely related to kidney function, and high contents of lactic acid are known to cause cirrhosis. Thus, it is important to realize the simple, rapid, and portable detection of disease-related trace substances in body fluids. Enzymes are catalytic organic molecules, most of which are proteins, but a small portion of which are RNA. When enzymes are induced by substrates, the conformation of the active center will change to form an enzyme-substrate complex. We note that enzymes have extremely high specificity, such that they can only catalyze the reaction of a certain structure or similar compounds. Enzymes have a broad range of applications in biosensing due to their specific and efficient catalysis of substrates. During the process of detecting target molecules, the liquid environment of the analytes that makes direct contact with the OSC may reduce the stability of the OFET device. To overcome this instability, the utilization of an extended-gate electrode is an ideal strategy for separating the detection portion from the drive unit. This extended-gate electrode can be flexibly modified according to the actual sensing demand. It is also convenient to change extended-gate electrodes according to the diversity of the analytes. As a result, many OFET enzyme biosensors apply an extended-gate structure. For example, Minami et al. [20-22] covalently cross-linked horseradish peroxidase with an osmium redox polymer to modify the extended-gate electrode, and found that lactate peroxidase or diamine oxidase could be immobilized on the modified extended-gate electrode to catalyze substrate decomposition and produce $\mathrm{H}_{2} \mathrm{O}_{2}$, thus triggering a redox reaction chain. Based on a change in the interface potential of the extended-gate electrode, which leads to a decrease in the channel conductance of the OFET, detection of lactate (Fig. 1a) and biogenic amines (Fig. 1b) can be realized.

For an OFET biosensor based on enzyme recognition unit, the stable immobilization and maximum biological activity of the enzyme are important factors. Hence, it is essential to immobilize the enzyme on the extended-gate surface, improve the immobilization efficiency, and maintain the biological activity of the enzyme.

Commonly used approaches for immobilizing enzymes include cross-linking, embedding, covalent bonding, and adsorption. In the cross-linking method, cross-linking agents, such as glutaraldehyde, $\mathrm{N}$-ethyl-N'-(3-dimethylaminopropyl) carbodiimide (EDC), and N,N'-diisopropyl carbodiimide (DIC), are essential. Glutaraldehyde is a homobifunctional cross-linking agent. Its two aldehyde groups can be coupled with a primary amino group comprising an enzyme and protein or other biomolecule to form a Schiff base $(-\mathrm{N}=\mathrm{C}-)$, which bridges the two molecules with a five-carbon chain to firmly immobilize the enzyme. EDC has been extensively applied to activate carboxyl groups followed by coupling reactions with amino group-containing molecules. Minami et al. [23] utilized a nitrate-reductase-modified extendedgate OFET for selectively detecting nitrate in water with a detection limit of approximately $45 \times 10^{-9}$, and successfully demonstrated its practical detection in diluted human saliva. In their study, glutaraldehyde and EDC were applied to immobilize nitrate reductase. First, a self-assembled monolayer (SAM) was formed on the extended-gate electrode by the interaction of 2-aminoethanethiol with gold, at which time amino groups were exposed to the electrode surface. After immersing the Au piece in a HEPES buffer solution containing N-methyl-N'-(carboxyethyl)-4,4'-bipyridine (BP), 1-hydroxybenzotriazole (HOBt), and EDC, EDC first activated the carboxyl group of BP to form an unstable intermediate. Then, HOBt reacted with the intermediate to form a stable active ester, which was covalently linked with the amino group of the SAM via an amidation reaction. This enabled the positively charged electron-transfer mediator (=BP) to be fixed onto the SAM layer. Finally, nitrate reductase was immobilized on the modified gate electrode by glutaraldehyde. The catalytic decomposition process requires cooperation of an electron donor and an electron mediator. Sodium dithionite in a solution can function as the electron donor of the enzyme, with BP as the electron-transfer mediator. This promotes the biocatalytic reaction of the reducing nitrate to a nitrite ion. When the enzyme reaction occurs, $\mathrm{BP}$ changes from $\mathrm{BP}^{2+}$ to $\mathrm{BP}^{+}$, and the ratio of the oxidized to the reduced state regulates the gate potential. By increasing the nitrate concentration in the solution, the transfer curve shifts negatively due to the impact of the potential change on channel conductance. Therefore, the nitrate detection mechanism could be explained by the electrical characteristics of OFET with electron relay (Fig. 1c). Generally speaking, the 
Fig. 1 Schematic illustration of the a lactate, $\mathbf{b}$ biogenicamines, and $\mathbf{c}$ nitrate sensing device based on the extended-gate type OFET biosensor

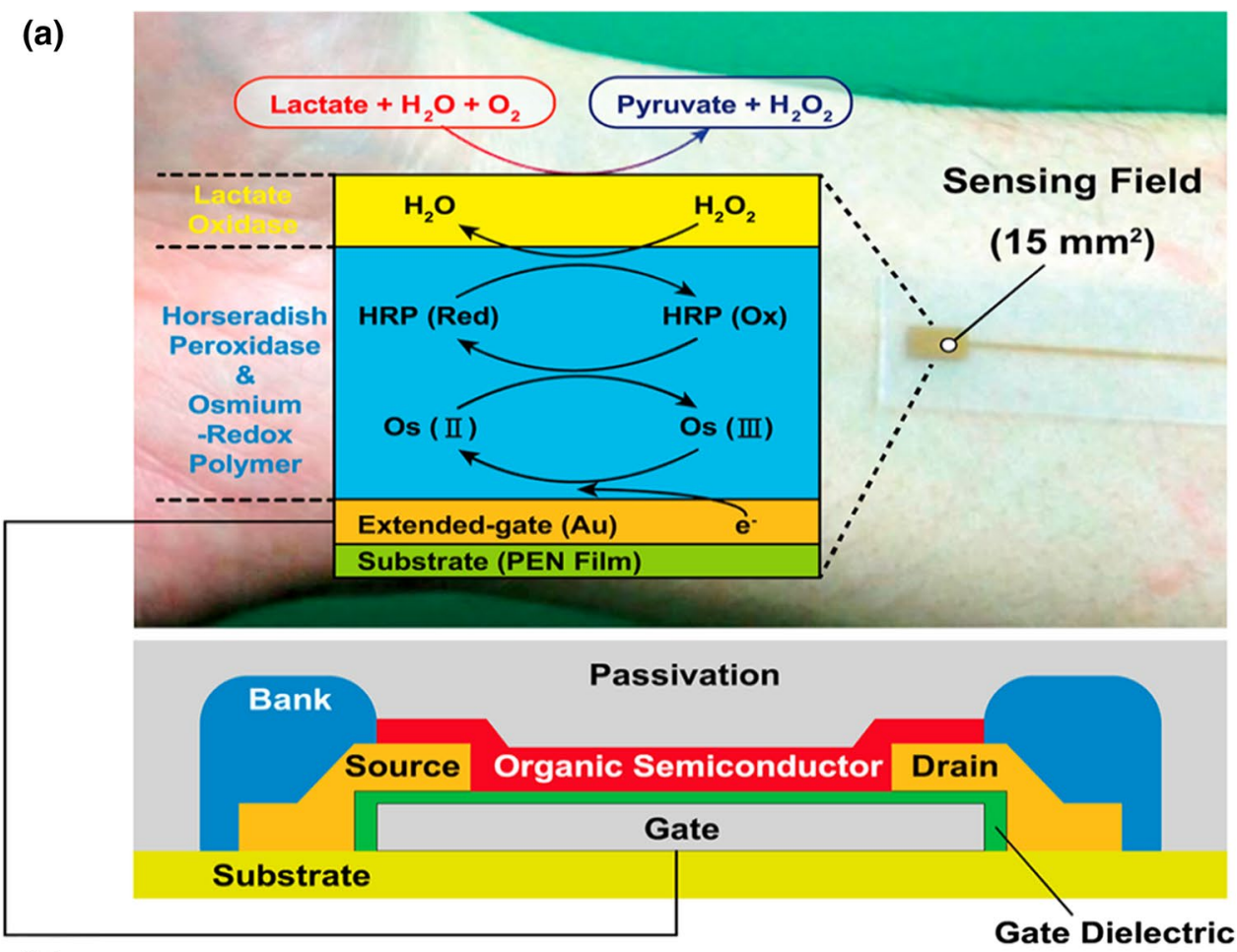

(b)

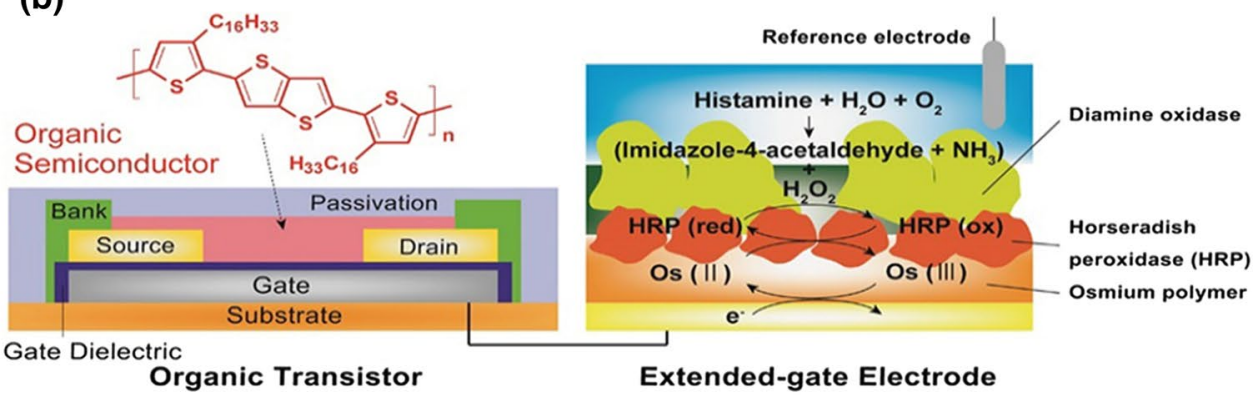

(c)

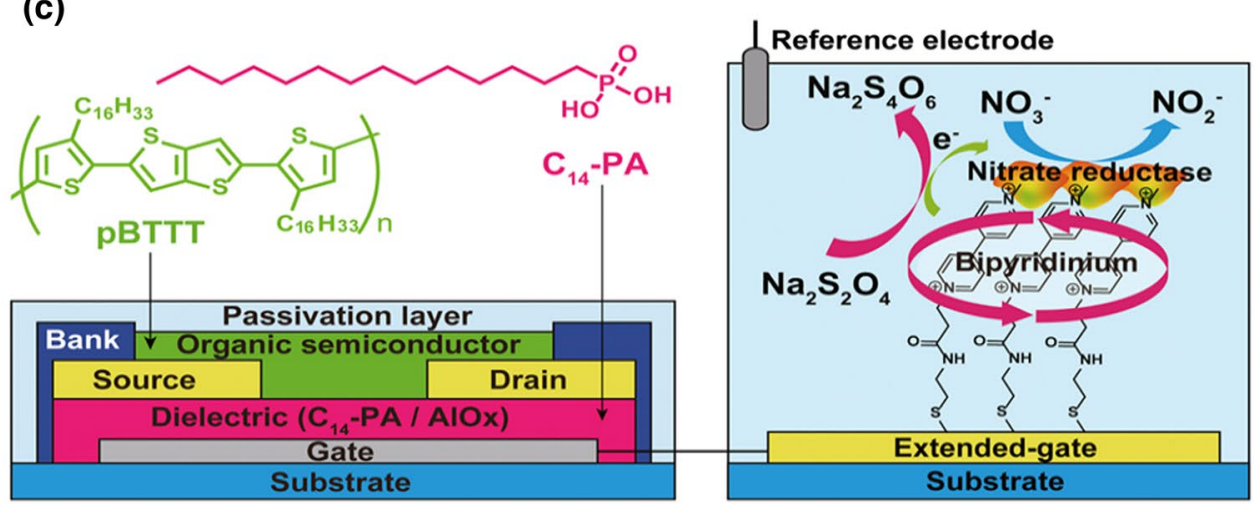

use of a cross-linking agent is a quick and simple method for enzyme immobilization, and the basic principle of using the extended-gate device (shown in Fig. 1) for detection is that the change in the surface potential of the extended gate causes a response in the conductive channel.

Werkmeister et al. [24] established a method for analyzing urea by the use of immobilized urease in catalyzing urea hydrolysis to produce ammonia. In their study, DNTT and parylene-C dielectric material with semipermeable membrane properties for ammonia were employed as the OSC layer and top gate, respectively. After oxygen plasma treatment of the activated gate surface, the functionalized gate was coupled with 3-aminopropyltriethoxysilane, and then, urease was covalently immobilized on the parylene-C 
membrane via a glutaraldehyde cross-linker. Charge-neutral ammonia $\left(\mathrm{NH}_{3}\right)$ molecules can diffuse into the OSC layer through a parylene-C film. Carriers can be captured in the OSC film, whereas ions and larger molecules are blocked. As a result, the current decreases rapidly in a short time, which enables the determination of the urea content.

In the process of cross-linking with glutaraldehyde or EDC, enzymes are prone to cross-linking among themselves, which results in lower coupling efficiency and lower enzyme activity. To overcome this problem, special heterobifunctional cross-linkers have been employed, for example sulfosuccinimidyl-4-(N-maleimidomethyl)cyclohexane1-carboxylate (sulfo-SMCC), which can effectively control the selectivity of the coupling reaction.

Due to their advantages of good biocompatibility, hydrophilicity, and non-toxicity, many natural organic substances can be used as carriers for enzyme immobilization. Furusawa et al. [25] used chitosan as a special immobilization carrier to immobilize glucose oxidase $\left(\mathrm{GO}_{x}\right)$ or pyran oxidase $\left(\mathrm{PO}_{x}\right)$. Usually, chitosan is insoluble in water but soluble in acidic solutions with a $\mathrm{pH}$ less than 6 . It has unique biochemical properties that include non-toxicity, environmental friendliness, and high protein affinity [26]. It can be converted into different forms according to the types of enzymes used. After immobilization, both the stability and activity recovery rate of the enzyme are enhanced, and the interference of metal ions is resisted. In this process, first, a $15-\mathrm{mm}^{2}$ gold film is deposited on the PET substrate to form an electrode. Then, a layer of carbon graphite ink with Prussian blue (PB) is coated on the gold film, and a mixture of $\mathrm{GO}_{x}$ or $\mathrm{PO}_{x}$ and chitosan is drop-casted onto the coating, which results in an enzyme-chitosan polyion complex film (Fig. 2b). Chitosan was found to be able to immobilize the enzyme on the Au electrode by electrostatic interaction to form a novel enzyme-chitosan hydrolyzed composite membrane. The amount of $\mathrm{Fe}^{3+}$ ions in $\mathrm{PB}$ was increased by the $\mathrm{H}_{2} \mathrm{O}_{2}$ generated via the oxidation of $\mathrm{GO}_{x}$, which results in an increase in the potential of the PB electrode compared to the reference electrode (Fig. 2c). As a sensing chip, the PET substrate can distinguish the sensing region from the sensor. The device can detect glucose and 1,5-anhydroglucitol at a concentration range of $1 \mathrm{mmol} / \mathrm{L}$ or more via the substrate-specific manner. For detection in real samples, corresponding measures should be taken to improve the signal-to-noise ratio and reduce the impact of random fluctuations. Since the redox reaction of PB is irreversible after an enzymatic reaction, the response of traditional extendedgate enzyme sensors to the analyte is one-time only. Mano et al. [27] fixed $\mathrm{GO}_{x} /$ chitosan on an extended-gate electrode modified by PB-carbon. By introducing an external resistor and simply modifying the circuit design, the extendedgate electrode was short-circuited with a reference electrode (compare Fig. 2a with Fig. 2d). The redox reaction of PB was induced reversibly by the redox potential difference of the electrode, and the continuous detection of D-glucose was realized. In addition, the enzyme biosensor was prepared by inkjet-printing technology, which achieved high sensitivity and flexibility without sacrificing device flexibility. This greatly promoted the development of wearable biosensors and realized the noninvasive monitoring of body fluids (such as biomarkers in tears, saliva, and sweat). Given that optimizing the sensor structure can significantly improve sensor performance, Elkington et al. [28] explored the influence of active-layer thickness and device structure on sensor performance. The results showed that removing the dielectric layer and reducing the thickness of the active layer can greatly reduce the response time and improve device sensitivity. It has been proved that the surface roughness of the deposited film can be further ameliorated by printing a $\mathrm{GO}_{x}$ layer on the Nafion film layer. This can avert the aggregation problems of Nafion: $\mathrm{GO}_{x}$ mixture, which readily leads to degradation of the device performance. The research of Elkington et al. provides an effective approach for low-cost glucose detection biosensors.

In addition to chitosan, sodium alginate gel is also a common carrier of immobilized enzymes. Sodium alginate aqueous solution has high viscosity. After adding calcium ions, the resulting ion exchange can produce a three-dimensional network structure that forms an ordered polymer domain. Alginate gel has good bioadhesion, biocompatibility, and biodegradability, and can be used as a carrier for biomolecules [29]. In addition, the conditions necessary for the sodium alginate cross-linking reaction are mild, which is suitable for embedding active molecules. Alginate gel can therefore act as a platform for building OFET biosensors with low toxicity, good safety, and good biocompatibility. In the electrolyte-gated OFET structure, high selectivity can be obtained if the biological receptor is directly connected to the electronic transduction channel. Dumitru et al. [30] used a gelatin capsule made of sodium alginate as the electrolyte gate (Fig. 3) in a transfer system for encapsulating biological macromolecules like $\mathrm{GO}_{x}$ and SA. This ion-permeable polymer electrolyte could form a double layer and operate at a low voltage of less than $0.5 \mathrm{~V}$. Considering its high biocompatibility and facility in taking multiple forms, the alginate-system gated OFET has broad application prospects in the field of biosensors. In this regard, the results obtained in the electronic detection of glucose/ $\mathrm{GO}_{x}$ reaction are noteworthy. The mild embedding conditions are beneficial for ensuring the structure and activity of the enzyme. Leakage and limited diffusion of the enzyme may occur because of the large size of the grid. Therefore, enzyme immobilization is usually combined with other strategies to achieve better immobilization and detection results.

The design and synthesis of OSC materials that can combine active groups of biological molecules is a direct strategy 
(a)

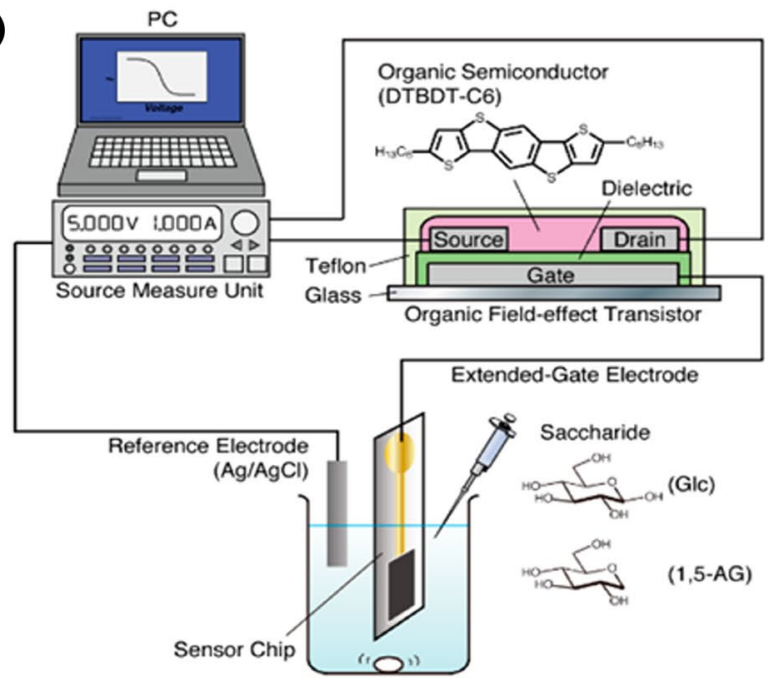

(b)
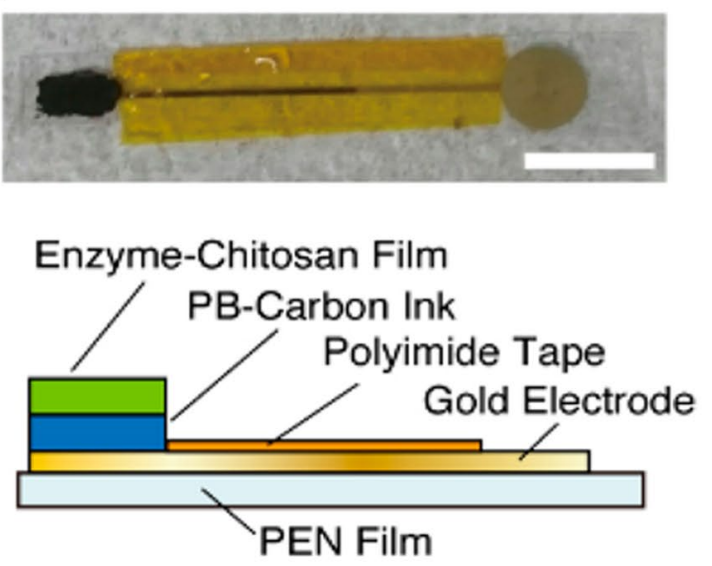

(c)

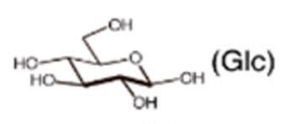

or

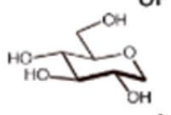

(1,5-AG)

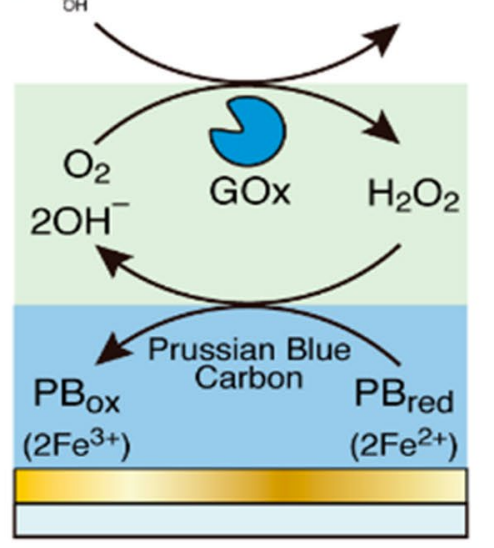

(Glconolactone)$$
\text { or }
$$

or

action
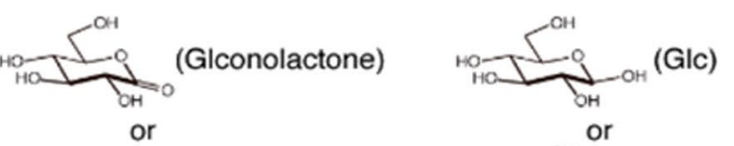

(O)

(1,5-AG)

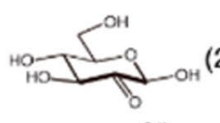

(2-dehydroglucose)

or

(2-dehydro-1,5-AG)
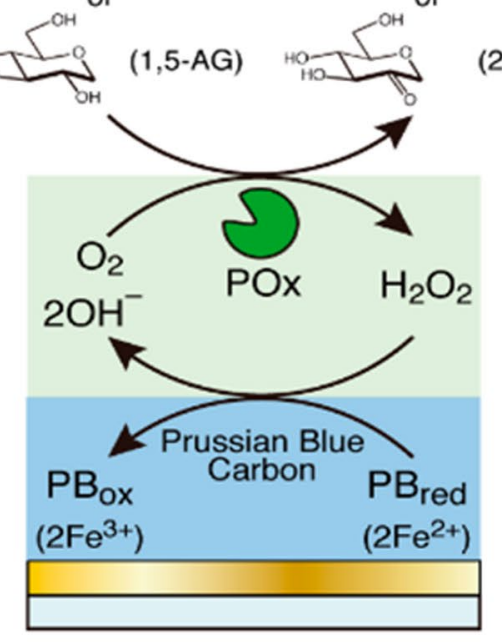

(d) $\mathrm{V}_{\mathrm{GS}}$

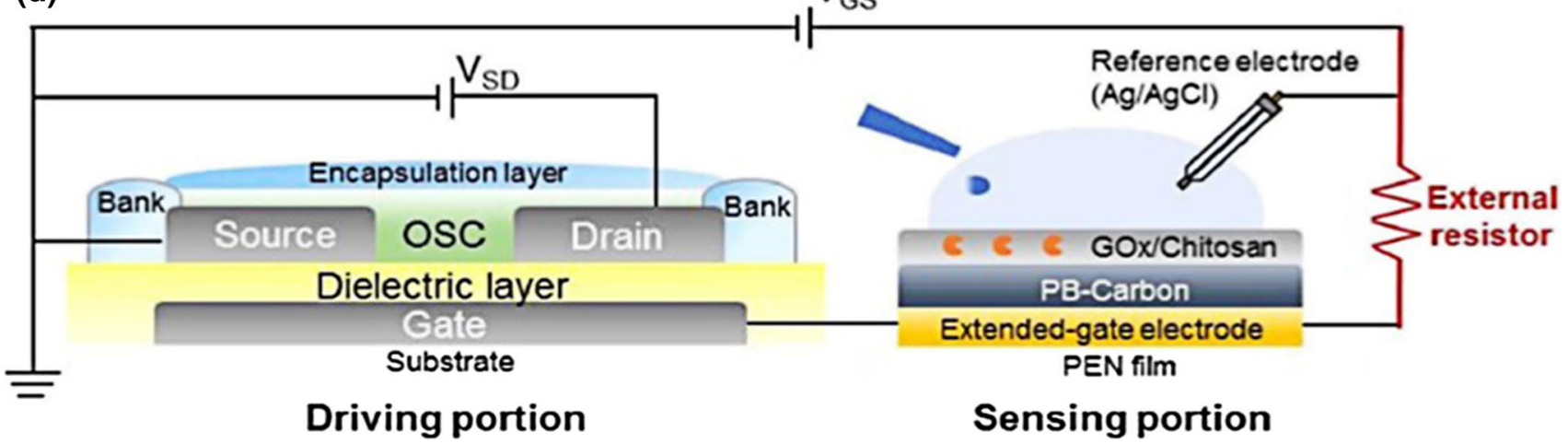

Fig. 2 a An illustration of an OFET-biosensor system using a sensor chip with an enzyme electrode for the potentiometric detection of saccharides. b A photograph and illustration of a sensor chip used in this study (white bar: $10 \mathrm{~mm}$ ). c Schematic illustrations of the reac- tion process of enzyme and PB in an enzyme electrode on the sensor chip (reprinted from [25] with permission from MDPI). d Schematic view of the structure of extended-gate type organic transistor-based enzyme sensor (reprinted from [27] with permission from Wiley) 
Fig. 3 Schematic illustration of the $\mathbf{a}$ alginate gelation process with divalent calcium cations and representation of the "egg-box" model for a calcium alginate structure. b Schematic illustration of the sodium alginate gel as a transfer system in electrolyte-gated OFET. c Schematic illustration of the gating effect in the alginate capsule gating the pBTTT-C14 OFET (reprinted from [30] with permission from AIP) (a)

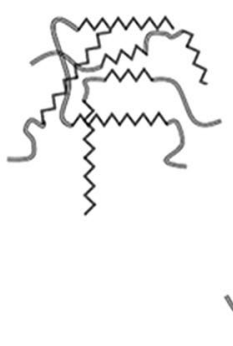
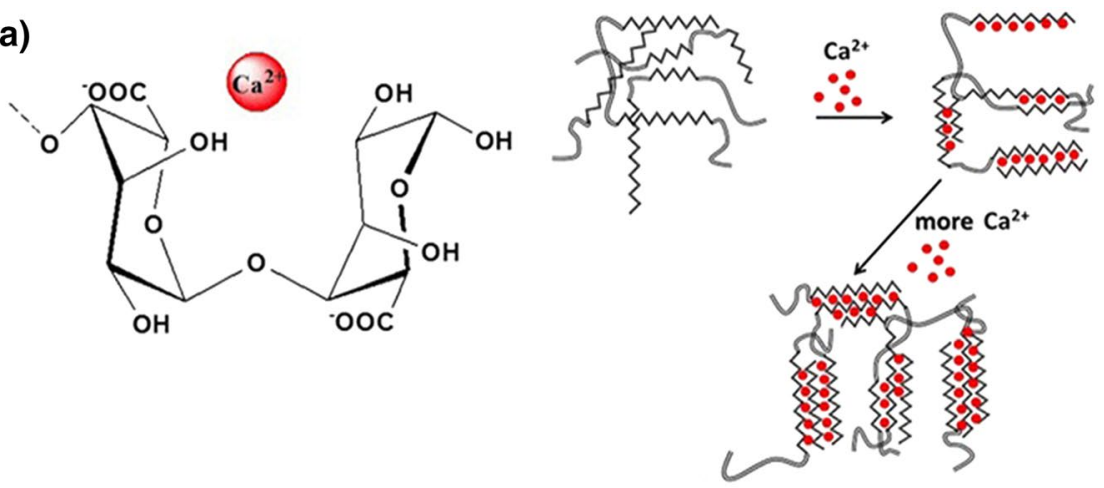

(b)

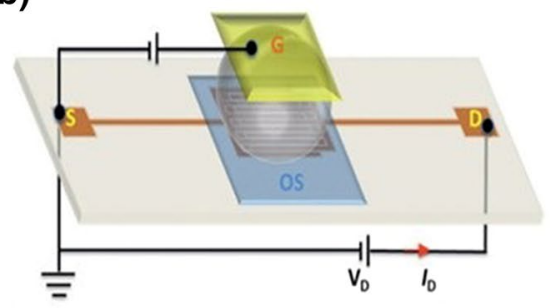

(c)

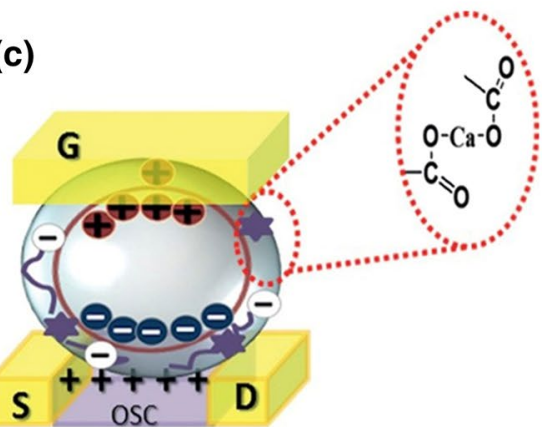

for the realization of direct interaction between the OSC and an analyte. However, most organic thin films cannot remain stable in the process of chemical modification. Shen et al. [31] used a plasma-assisted in situ microdamage interfacial grafting approach to treat the conductive channel of the OSC layer, which can control the position of the functional interface and introduce a neighboring-conductive channel layer (NCCL) with specific binding groups in situ (Fig. 4a). X-ray (a)

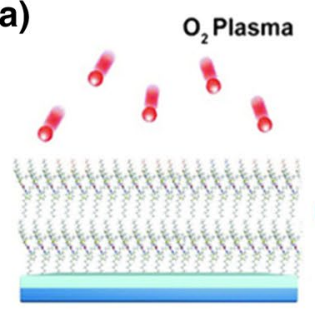

(b)
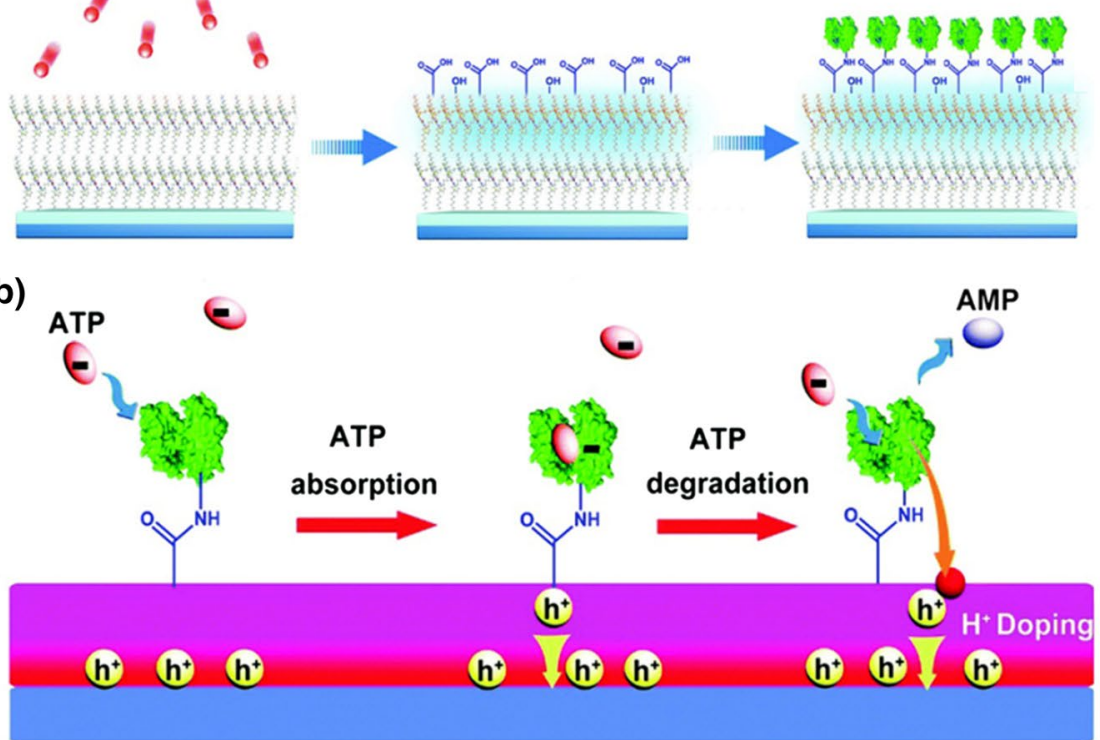

(c)
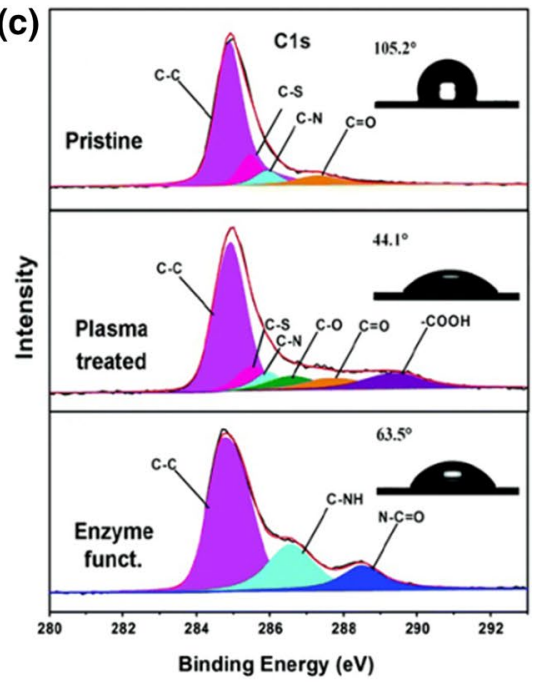

Fig. 4 Schematic of a the PIMIG approach to introduce binding groups and subsequently immobilize enzymes onto the surfaces of OSCs. b Schematic illustration of the proposed sensing mechanisms of the ATP biosensor. $\mathrm{c}_{2}$ plasma treated ( $\left.24 \mathrm{~W}, 2 \mathrm{~min}\right)$, and enzyme modified OTFTs. XPS spectra and static contact angle for pristine, $\mathrm{O}_{2}$ plasma treated ( $24 \mathrm{~W}, 2 \mathrm{~min}$ ), and the enzyme immobilized PDPP3T film (reprinted from [31] with permission from RSC) 
photoelectron spectroscopy showed that most of the surface functional groups of PDPP3T were $-\mathrm{COOH}$ groups after $\mathrm{O}_{2}$ plasma treatment. A signal peak appeared in the $\mathrm{C}-\mathrm{NH}$ $(286.2 \mathrm{eV})$ and $\mathrm{O}=\mathrm{C}-\mathrm{NH}(288.3 \mathrm{eV})$ groups suggests that the enzyme was immobilized on the PDPP3T layer by covalent bonds (Fig. 4c). Ultraviolet photoelectron spectroscopy analysis revealed that the carboxylic acid group content reached $11.2 \%$. The high-density and high-activity carboxylic acid group facilitated the immobilization of the hydrolytic enzyme, adenosine, as the receptor for the detection of adenosine triphosphate (ATP). Atomic force microscopy imagery showed that the OSC layer was densely covered with nanoparticle-type structures, confirming the successful immobilization of the ATP hydrolase. The ATP hydrolasemodified NCCL acted as the sensing antenna (Fig. 4b). The semiconductor in the channel interacted directly with the target analyte in solution to maintain effective chargetransport characteristics with a limit of detection as low as $0.1 \mathrm{nmol} / \mathrm{L}$. In view of its flexibility and good uniformity of performance, the organic thin-film transistor can be successfully applied to flexible sensor arrays, and its application prospect is particularly important in portable medical diagnosis sensors.

Table 1 shows a summary of all the sensing methods described in this section for comprehensive comparison.

\section{Immobilization Strategies of Antibody}

\section{Antibody Immobilization Strategies on Gate}

The production of many antigens may be related to certain diseases in the body. Generally, antigen detection is required and performed in vivo in the latent, acute, or early stages of a disease. The quantitative and qualitative detection of antigens is achieved by taking advantage of the strong affinity between antigens and antibodies (Abs) on OFET sensor platforms. The efficient immobilization of Abs is a significant step in the implementation of analyte detection by OFETs, in which the aim is to maximize the binding of the antibody to the antigen, along with the required activity, conformation, and spatial orientation [32].

It is well known that ordered alkanethiols can form $\mathrm{S}-\mathrm{Au}$ bonds with gold and they are widely used to fabricate SAMs in sensors. SAMs have the advantages of orderly compact arrangement, self-growth in situ, high coverage of the substrate, and few defects. Usually, one end of a SAM is connected to the gold surface by chemical bonds and the other end provides binding sites for the immobilization of biological molecules. However, SAMs with different chain lengths result in different distances between the antibody and electrode. If the molecular weight of the antibody is too large, the detection sensitivity and reproducibility may be reduced [33]. Therefore, when immobilizing $\lg$ A (immunoglobulin A, $\operatorname{lgA}$ ) Abs with a relative molecular weight of $160 \mathrm{kDa}$, Minamiki et al. used 3-mercaptopropionic acid (3-MPA) with shorter chains to fabricate the SAM [34].

The end of an SAM usually contains carboxyl (amino) groups to which the amino (carboxyl) groups of biological molecules can be coupled using a coupling agent, which provides favorable conditions for immobilization. In the qualitative and quantitative detection of Abs and antigens, the high affinity and multi-stage amplification effect between SA and biotin are widely applied [35]. For instance, Minamiki's group [36] used 5-carboxy-1-pentanethiol (CPT) to grow a SAM on a gold surface when an anti-human chromogranin $\mathrm{A}$ (hCgA) monoclonal antibody fixed on the extended-gate electrode surface was used to detect $\mathrm{hCgA}$. The combination of N-hydroxysulfosuccinimide (sulfo-NHS) and EDC (or DIC) within a specific concentration range enables the complete activation of the carboxyl group and stabilizes the active intermediates to improve the coupling efficiency [37].

Table 1 Summary of OTFT platforms based on enzyme-substrate-specific binding detection

\begin{tabular}{|c|c|c|c|c|c|}
\hline Device & Biomaterial & Immobilization method & Detection linear range & Limit of detection & References \\
\hline \multirow[t]{5}{*}{ Extended-gate OFET } & Lactate peroxidase & Cross-linking & $0-1000 \mathrm{nmol} / \mathrm{L}$ & $66 \mathrm{nmol} / \mathrm{L}$ & [20] \\
\hline & Diamine oxidase & Cross-linking & $0-10 \mu \mathrm{mol} / \mathrm{L}$ & $1.2 \mu \mathrm{mol} / \mathrm{L}$ & {$[22]$} \\
\hline & Nitrate reductase & Cross-linking & $0-4.0 \times 10^{-6} \mathrm{~mol} / \mathrm{L}$ & $45 \times 10^{-9}$ & {$[23]$} \\
\hline & ${ }^{\mathrm{a}} \mathrm{GO}_{x} /{ }^{\mathrm{b}} \mathrm{PO}_{x}$ & Adsorption & $0-10 \mathrm{mmol} / \mathrm{L}$ & $1 \mathrm{mmol} / \mathrm{L}$ & [25] \\
\hline & $\mathrm{GO}_{x}$ & Adsorption & $0-51.2 \mathrm{mmol} / \mathrm{L}$ & $c_{-}$ & {$[27]$} \\
\hline \multirow[t]{3}{*}{ OFET } & Urease & Cross-linking & $0.75-7.5 \mathrm{mmol} / \mathrm{L}$ & - & {$[24]$} \\
\hline & $\mathrm{GO}_{x}$ & Inkjet printing & $0.1-100 \mathrm{mmol} / \mathrm{L}$ & - & {$[28]$} \\
\hline & ATP hydrolase & Covalent binding & $1.0 \times 10^{-5}-10 \mathrm{mmol} / \mathrm{L}$ & $0.1 \mathrm{nmol} / \mathrm{L}$ & {$[31]$} \\
\hline Electrolyte-gated OFET & $\mathrm{GO}_{x}$ & Embedding & - & - & [30] \\
\hline
\end{tabular}

${ }^{a}$ Glucose oxidase

${ }^{\mathrm{b}}$ Pyranose oxidase

${ }^{\mathrm{c}}$ Not mentioned 
The biotin-tagged anti-CgA antibody was then immobilized by the interaction between SA and avidin with a detection limit of $0.11 \mu \mathrm{g} / \mathrm{mL}$ (Fig. 5).

However, this method for coupling carboxyl to an amino group is random and cannot effectively control the spatial orientation of the antibody. The density, spatial orientation, conformation, and stability of antibody immobilization greatly influence the detection sensitivity, so suitable and effective immobilization methods are particularly important for effective detection. In addition, since the extended-gate electrode is separated from the sensing region, the response sensitivity of the device is somewhat weakened in comparison with other test results [38]. Using an electrolyte-gated OFET biosensor, the sensitivity of the device response can be improved by the introduction of a biorecognition unit into any active interface of a gate-electrolyte or electrolyte-semiconductor, in which both the gate electrode and OSC layers can be used as immobilized biomolecule surfaces.

Casalini et al. [39] evaluated different strategies for immobilizing interleukin-4 (IL 4) Abs on a gold electrode using an electrolyte-gated OFET. In the first scheme, the authors generated a glutaraldehyde-activated 6-aminohexanethiol $\left(\mathrm{HSC}_{6} \mathrm{NH}_{2}\right) \mathrm{SAM}$ on the gate. This functionalization method relied on chemical bonding between the side chains of the lysine residues and $\mathrm{Au}$, and the direction of the antibody cannot be effectively controlled with respect to the natural abundance of lysine in the antibody. The Histagged protein $\mathrm{G}(\mathrm{PG})$ has a strong affinity for a $\lg \mathrm{G}$ heavy chain and could be used as a primer to connect Abs to the receptor layer in a more orderly and uniform direction. Consequently, the second strategy exploited the recombinant PG whose $\mathrm{N}$-terminus was tailored by means of a 6-histidine chain to immobilize the Abs in a certain orientation to the Au surface. Ideally, PG binds specifically to fragment crystallizable of Abs [40], whereas fragment antigen-binding $(\mathrm{F} a b)$ stretches toward the liquid phase, so that Abs can maintain their natural conformation and expose more free antigen-binding regions. Thus, controlling the directional arrangement of Abs can increase the sensitivity of the biosensor. The results showed that the area density of the Abs/ PG/Au structure was enhanced by targeted immobilization. The active Abs was also oriented more intensively on the surface toward IL 4 (Fig. 6), and the detection limit of the IL 4 was $5 \mathrm{nmol} / \mathrm{L}$.

The His-tagged PG immobilization strategy is reported to achieve substantially uniform coverage and targeted binding of active Abs, and can effectively detect analytes in complex media. Berto et al. [41] directly modified a gold electrode with recombinant cysteine protein $\mathrm{G}$ (Cys-Protein $\mathrm{G}$ ) to function as the binding site of the antibody against the plum pox virus, and used a (11-mercaptoundecyl)tri(ethylene glycol) (OEG) SAM to seal the gold electrode surface to avert non-specific adsorption of the portion not covered by the protein/antibody structure. The cyclic voltammetry results showed that the Faradic response was completely inhibited by OEG SAM functionalization, with no non-specific adsorption sites remaining on the gate electrode surface. The coverage of the Au electrode by PG/Ab was $42( \pm 2) \%$.

\section{Immobilization Strategies of Antibody in OSC Layer}

Most of the surface functionalization strategies used in organic transistor biosensors are based on the chemical modification of the gate electrode to provide binding sites for biomolecules to realize biometric identification. For OSCs with bioaffinity binding capacity (or side chain groups) [42], placing the biorecognition layer on the (or modified) OSC surface is ideal for biomolecule immobilization.

The functionalization of OSCs can cause a change in the mobility sensitivity of carriers in the channel. To minimize these effects on the OSC, Piro et al. [43] used strategies involving the non-covalent processing of the OSC layer to anchor antigens. In that study, the authors performed alkylation of bisphenol A (BPA) with 1-bromohexaneto synthesize
Fig. 5 Schematic illustration of the OFET-based immunosensor (reprinted from [36] with permission from MDPI)

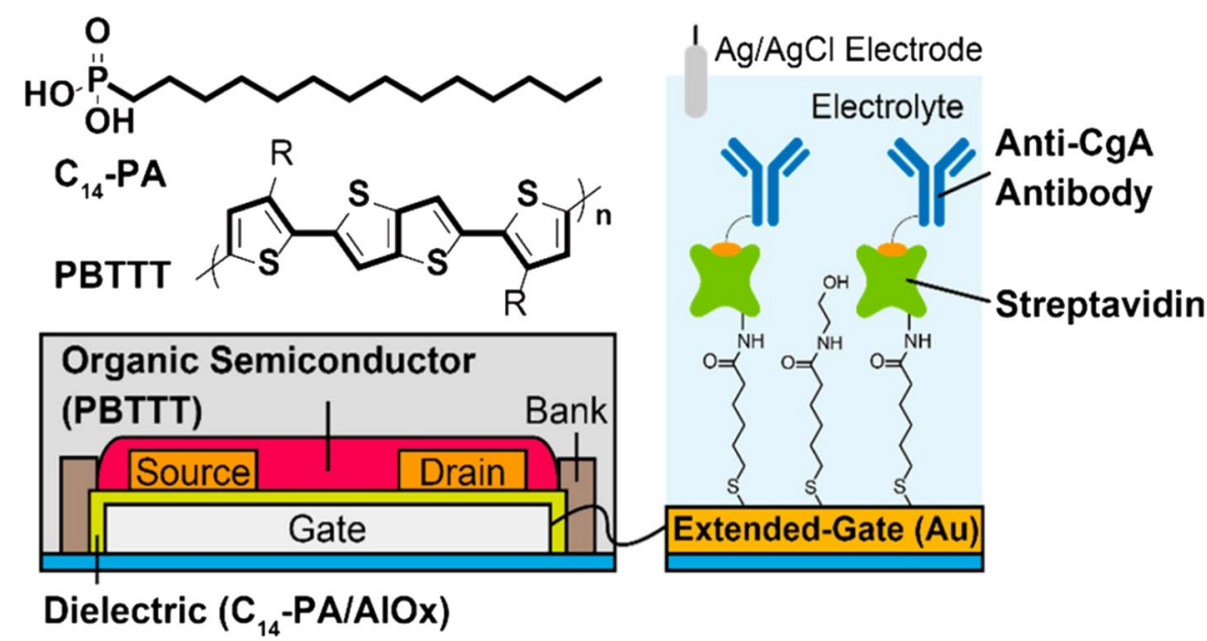


Fig. 6 Nyquist plots of a HSC6NH2- and b PG-mediated treatment. On the top part of these plots, a cartoon of the two functionalization strategies is shown (reprinted from [39] with permission from ACS) (a)
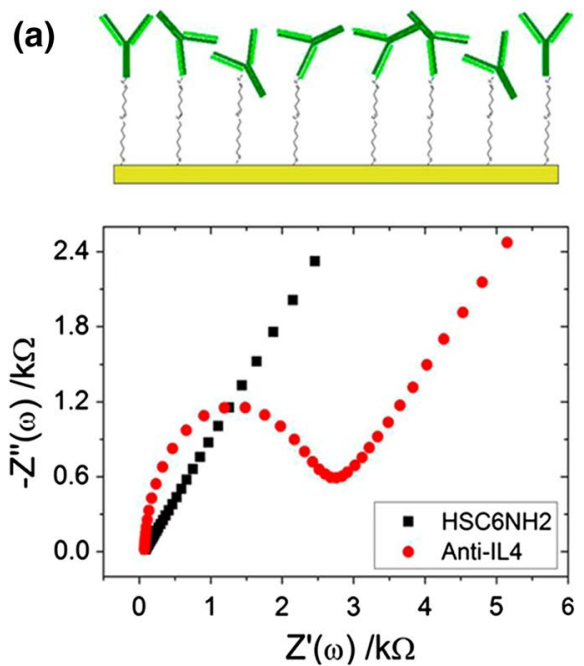

(b)
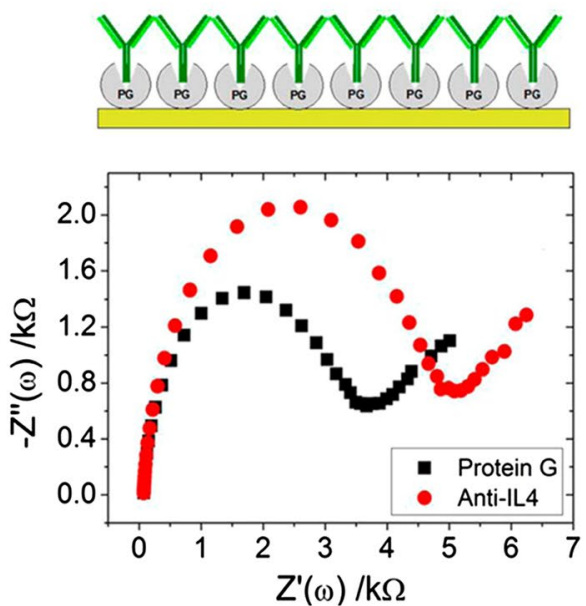

${ }^{a l k}$ BPA containing six straight chains of carbon atoms as a target mime (hapten), which promoted a Van der Waals interaction with the OSC (pBTTT) alkyl chain. These components were blended in a certain proportion and then spincoated as the OSC layer. This method required no chemical modification of pBTTT or covalent immobilization of antigens. The ${ }^{\text {alk }}$ BPA hapten was immobilized on the OSC as a capture probe for anti-BPA. In the first stage, the antibody in the solution binds to the target hapten on the pBTTT. When BPA is present in the solution as a native target, the immobilized mime and the diffusing target engage in a competitive exchange, which removes the antibody from the surface to displace the equilibrium. Large Abs were found to cause recombination at the channel-electrolyte interface, which increases the capacitance and thus the output current (Fig. 7a) with responses up to the $\mathrm{nmol} / \mathrm{L}$ range. In addition to bisphenol A, this transduction structure can theoretically be extended to the detection of any small organic pollutants if the substance to be tested had immunogenicity and specific Abs.

However, the covalent or non-covalent functionalization of the OSC is usually disadvantageous and can lead to a significant degradation in device performance. From a practical point of view, for immobilizing biomolecules on the surface of the OSC layer and maintaining its electrical properties, physical adsorption is a relatively fast method that typically depends on the inter-molecular Van der Waals force, hydrophobic interactions, and ion-hydrogen bonding interactions. Magliulo et al. [45] proposed the physical adsorption of C-reactive protein (CRP) monoclonal Abs on the OSC layer, poly-3-hexylthiophene (P3HT), for the ultrasensitive detection of CRP. This antibody immobilization process requires no pretreatment on the OSC surface. The immobilization of the receptor by physical adsorption was found to have little effect on the performance of the OSC, and the surface coverage density of the antibody protein in
P3HT was $200 \pm 30 \mathrm{ng} / \mathrm{cm}^{2}$. The hydrophobic lipoate group of the nonionic hydrophilic polymer (pTHMMAA) can be physisorbed onto the surface of $\mathrm{P} 3 \mathrm{HT}$ and inserted between antibody molecules. As a blocking agent, loosely bound protein residues can be removed, non-specific adsorption can be reduced, and the antibody can be better immobilized, thereby providing a good hydrophilic environment for proteins. The entire functionalization process was reported to be quick and simple, and the surface plasmon resonance results showed that the antibody coverage of CRP was effectively detected to be about $23 \%$. Similarly, Seshadri et al. [46] used a physical adsorption method to directly immobilize procalcitonin (PCT) specific Abs on the P3HT OSCs, blocked by BSA to prevent non-specific adsorption. The antibody and BSA acted as a biorecognition layer to selectively capture procalcitonin target analytes. When the analyte was added, the authors found the threshold voltage of the device to change significantly. Probably because the top of the semiconductor layer was permeable to ions, the surface negative charges of the analyte PCT acted as trap sites to induce positive charge carriers (holes) in the P3HT.

In summary, for the functionalization of the OSC layer, although physical adsorption cannot avoid the random orientation of biomolecules, the influence of complex chemical modification processes on the activity of OSC layers and biomolecules may be more difficult to control. In practice, it is necessary to make the most beneficial choices according to the situation of the OSCs.

\section{Immobilization Strategies of Proteins by Receptor Layer}

To achieve greater density and more secure immobilization of biological molecules, target functional materials are usually employed as receptor layers. Song et al. [47] studied the stability of poly styrene-co-methacrylic acid 
(a)

Au gate

Competitive decomplexation

of alkyl-BPA

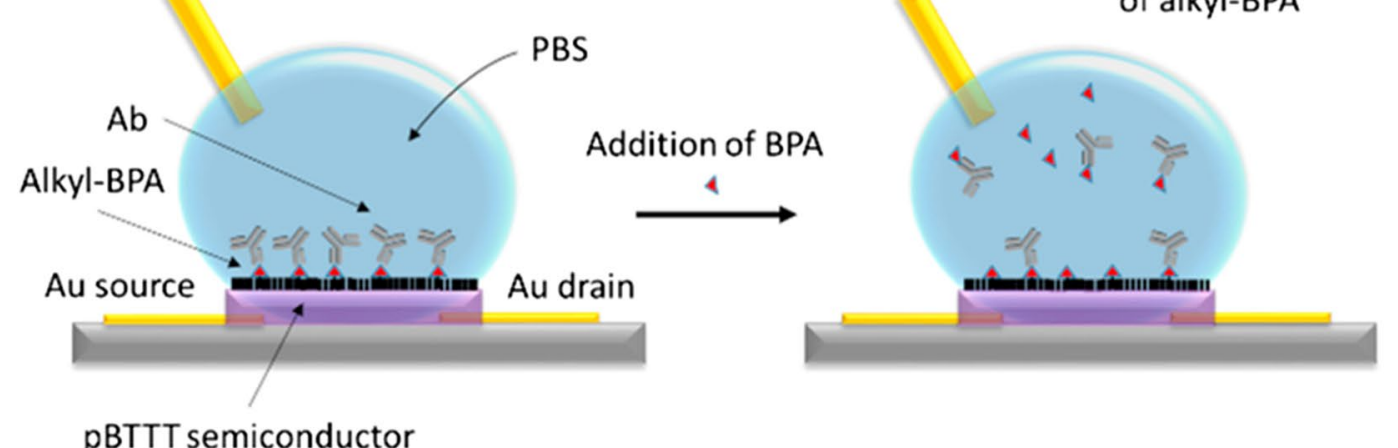

pBTTT semiconductor

\begin{tabular}{cc} 
Symbol & Description \\
\hline BPA & Bisphenol A diffusing in the electrolyte
\end{tabular}

(b)

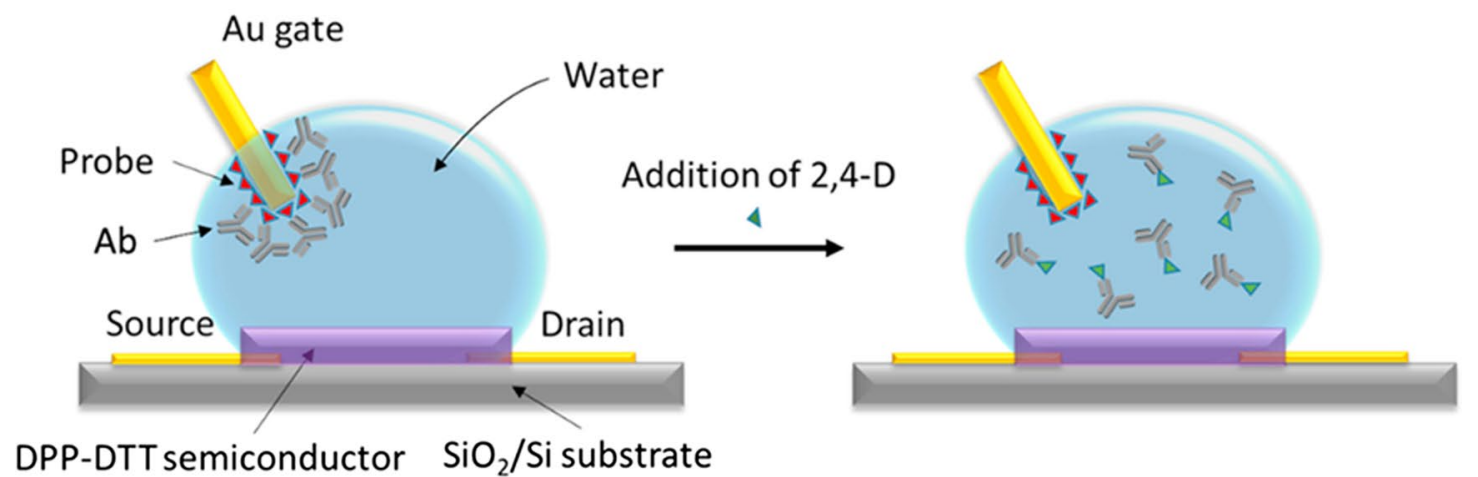

Fig. 7 a Competitive immunodetection at the semiconductor/electrolyte interface of the BPA-EGOFET, and the symbol, formula, and description of BPA-EGOFET (reprinted from [43] with permission from Elsevier). b Schematic illustration of the gate-modified EGO-
FET, before (left) and after (right) addition of the target molecule 2,4-D in the electrolyte (reprinted from [44] with permission from Elsevier)

Theoretically, materials with a high carboxyl density could immobilize more antibody molecules. However, although PDLLA-PAA had the highest carboxyl density, its antibody immobilization ability was poor, as was that of PSPAA. PS-MA and PMMA-MA had stronger immobilization effects on Abs, but the Abs immobilized by the PMMA-MA 
receptor layer tended to aggregate extensively, which limited the range of MBP accessibility and binding. PS-MA had the highest intensity and the largest amount of immobilized Abs. In addition, carboxyl groups with high number densities in the receptor-layer materials were not conducive to washing stability, and the results of repeated washes showed PS-MA to have the best stability. Therefore, PS-MA can act as a good receptor layer for immobilizing biomolecules. The acceptor-layer material should have an optimized carboxyl concentration to balance washing stability with the capacity to couple receptors. These conclusions provide a basis for the selection of biological receptor materials to improve the sensitivity and process stability of OFET biosensors.

Mulla et al. [48] proposed an innovative way to spincoat a thin layer of poly(acrylic acid) (PAA) on the top of PBTTT, and then UV-cross-linked PAA to obtain highdensity $-\mathrm{COOH}$ groups anchored on the surface of OSC film (Fig. 8). The authors covalently linked phosphatidylethanolamine in phospholipid bilayers to the OSC layer via an EDC/NHS amine coupling reaction, and found the bilayer membrane containing biotinylated phospholipids (B-PL)s can serve as bioprobes, which immobilized on the PAA coating to providing sites for SA. In addition, the PAA layer cross-linked by UV radiation was reported to maintain higher stability in aqueous solution, which is critical to maintaining good electrolyte-gated OFET performance. Due to the formation of a "Donnan's equilibrium" within the protein layer, this sufficiently low extra capacitance was connected in series to the gating system to detect protein binding events occurring at 30 times the Debye's length and EGOFETs successfully operated in high ionic strength solutions. We note that PBTTT is a photosensitive polymer that can become slightly degraded under ultraviolet light, resulting in a decrease in mobility.

\section{Immobilization Strategies of Aptamers and Other Molecules}

Immunological recognition between a biomarker and immobilized antibody is restricted by factors such as size and orientation. It is also difficult to obtain a recognition layer with a high surface density. A biometric layer that is as thick as several tens of nanometers is far beyond the Debye screening length, which makes detection difficult. Therefore, biometric identification must overcome the Debye length effect [49, 50] or establish smaller identification units.

Using small-size peptide aptamers has attracted great research interest. Diacci et al. [51] immobilized the peptide aptamers (Affimers ${ }^{\mathrm{TM}}$ ) of interleukin-6 (IL 6) on an electrolyte-gated electrode to determine the recognition effect of the aptamer on biomarkers. The peptide aptamers exhibited an affinity similar to that of monoclonal Abs to IL 6, so they can be used to quantify biomarkers. Berto et al. [52] first used His-Tag PG to immobilize the pro-inflammatory cytokine antibody for tumor necrosis factor alpha (TNF $\alpha$ ) on the surface of a gold electrode, and demonstrated that gate voltage is the key factor for tuning the device sensitivity. In subsequent work, the authors realized the ultralow detection of TNF $\alpha$ in complex solutions such as a cell culture medium of $10 \%$ serum, which had obvious ligand specificity [53].

By the use of low-molecular-weight receptors such as aptamers, the binding reaction can be restricted to the electrical double layer to avoid the unresponsiveness problem associated with the Debye length effect. To overcome the restrictions of molecular weight and Debye length of the receptor, Nguyen et al. [44] synthesized 2,4-dichlorophenoxyacetic acid (2,4-D) derivative molecular probes by electro-grafting diazo salt to functionalize the gate electrode.
Fig. 8 Schematic illustration of the EGOFET biosensing platform fabrication process. After deposition of the PBTTT OSC on the substrate a poly(acrylic acid) coating is spin-coated and cross-linked by UV radiation exposure. Biotinylated phospholipids are anchored as bioprobes on the PAA coating through the EDC/NHS amine coupling chemistry. The electrical and sensing measurement are performed with an electrolyte-gated organic filed-effect transistor comprising a gold gate electrode and a droplet of PBS as a dielectric medium (reprinted from [48] with permission from RSC)
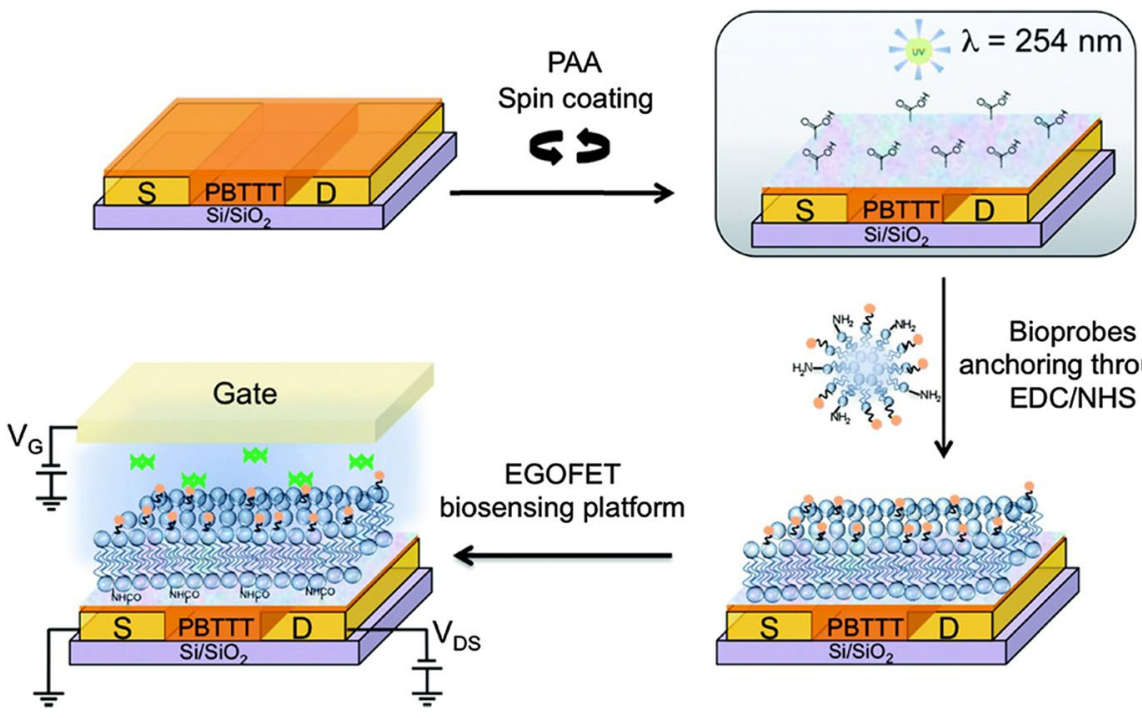
These molecular probes acted like hapten and could bind to 2,4-D-specific Abs. The gold microelectrode performed scanning by applying a certain range of voltage in the diazo salt solution, which produced an insoluble thin layer on the metal electrode and completed the gate functionalization. The freely diffusing 2,4-D regained complexation equilibrium by competitively binding with the antibody, which removed the antibody-antigen from the gate surface. The detection limit was approximately $2.5 \mathrm{fmol} / \mathrm{L}$ (Fig. 7b). The detection method described by Nguyen et al. can be used to more accurately describe the pollution level and achieve practical application. This competitive immunodetection scheme can successfully detect the analyte. With hapten as the probe to capture the antibody, a competitive equilibrium is established to achieve good detection results after the addition of antigens.

For molecules with a sulfhydryl group, the affinity between the HS group and gold surface can be directly used to realize the functionalization of the gate electrode. For example, de Oliveira et al. [54] directly immobilized glutathione (GSH) using the cysteine residues (Cys) of GSH, and explored the biospecific interaction between GSH and glutathione S-transferase enzymes.

To make an overall comparison of various assays, Table 2 shows a summary of the immobilization media, modified interfaces, and detection performances of various proteins.

\section{Immobilization Strategies of DNA}

DNA molecules can form a stable double helix structure by hydrogen bonding via the principle of complementary base pairing. The hybridization process of a DNA molecule has high specificity and sensitivity. The introduction of a DNA molecule into an OFET sensor platform can not only enhance device performance, but also detect the target sequence based on the hybridization principle of DNA molecules. In a DNA molecular hybridization experiment, Lai

Table 2 Summary of modified interface based on fixed Abs and other proteins

\begin{tabular}{|c|c|c|c|c|c|}
\hline Modified interface & Biomaterial & Immobilization media & Detection linear range & Limit of detection & References \\
\hline \multirow[t]{9}{*}{ Gate } & ${ }^{\mathrm{a}} \lg \mathrm{A}^{\mathrm{b}} \mathrm{Abs}$ & '3-MPA SA & $0-10 \mu \mathrm{g} / \mathrm{mL}$ & $2.1 \mu \mathrm{g} / \mathrm{mL}$ & [34] \\
\hline & ${ }^{\mathrm{d}} \mathrm{hCgA} \mathrm{Abs}$ & ${ }^{\mathrm{e}} \mathrm{CPT} \mathrm{SA}$ & $\mathrm{f}_{-}$ & $0.11 \mu \mathrm{g} / \mathrm{mL}$ & {$[36]$} \\
\hline & Interleukin-4 Abs & $\mathrm{HSC}_{6} \mathrm{NH}_{2} /$ His-Tag PG & - & $5 \mathrm{nmol} / \mathrm{L}$ & [39] \\
\hline & Plum pox virus Abs & Cys-Protein G & $5 \mathrm{ng} / \mathrm{mL}-50 \mu \mathrm{g} / \mathrm{mL}$ & $180 \mathrm{pg} / \mathrm{mL}$ & [41] \\
\hline & gIL6 Abs/aptamers & His-Tag PG/- & $1 \mathrm{pmol} / \mathrm{L}-10 \mathrm{nmol} / \mathrm{L}$ & $1 \mathrm{pmol} / \mathrm{L}$ & {$[51]$} \\
\hline & ${ }^{\mathrm{h}} \mathrm{TNF} \alpha \mathrm{Abs}$ & His-Tag PG & $100 \mathrm{mmol} / \mathrm{L}-10 \mathrm{nmol} / \mathrm{L}$ & $0.8 \mathrm{nmol} / \mathrm{L}$ & {$[52]$} \\
\hline & TNF $\alpha$ aptamers & - & $10^{-12}-10 \times 10^{-9} \mathrm{~mol} / \mathrm{L}$ & $1 \times 10^{-12} \mathrm{~mol} / \mathrm{L}$ & {$[53]$} \\
\hline & i 2,4-D hapten & Diazonium group & $10^{-16}-10^{-13} \mathrm{~mol} / \mathrm{L}$ & $2.5 \mathrm{f} \mathrm{mol} / \mathrm{L}$ & [44] \\
\hline & Glutathione & Cys & - & - & {$[54]$} \\
\hline \multirow[t]{3}{*}{ OSC } & j alk BPA & ${ }^{\mathrm{k}} \mathrm{pBTTT}$ & $10^{-6}-10^{-12} \mathrm{~mol} / \mathrm{L}$ & $2 \mathrm{pg} / \mathrm{mL}$ & [43] \\
\hline & ${ }^{\mathrm{l}} \mathrm{CRP} \mathrm{Abs}$ & - & $4 \mathrm{pmol} / \mathrm{L}-2 \mu \mathrm{mol} / \mathrm{L}$ & $2 \mathrm{pmol} / \mathrm{L}$ & [45] \\
\hline & Procalcitonin Abs & - & $0.8 \mathrm{pmol} / \mathrm{L}-4.7 \mathrm{nmol} / \mathrm{L}$ & $2.2 \mathrm{pmol} / \mathrm{L}$ & [46] \\
\hline \multirow[t]{2}{*}{ Receptor layer } & ${ }^{\mathrm{m}} \mathrm{MBP}$ Abs & ${ }^{\mathrm{n}} \mathrm{PS}-\mathrm{MA}$ & - & $1 \mathrm{ng} / \mathrm{mL}$ & [47] \\
\hline & ${ }^{\circ}(\mathrm{B}-\mathrm{PL}) \mathrm{s}$ & Poly(acrylic acid) & $0.01 \mathrm{nmol} / \mathrm{L}-1.6 \mathrm{mmol} / \mathrm{L}$ & $10 \mathrm{pmol} / \mathrm{L}$ & {$[48]$} \\
\hline
\end{tabular}

${ }^{\mathrm{a}}$ Immunoglobulin A

${ }^{\mathrm{b}} \mathrm{Abs}$

c3-mercaptopropionic acid

${ }^{\mathrm{d}}$ Human chromogranin A

e 5-carboxy-1-pentanethiol

${ }^{\mathrm{f}}$ Not mentioned

${ }^{\mathrm{g}}$ IL-6 represents interleukin-6

${ }^{\mathrm{h}}$ Tumor necrosis factor a

i 2,4-dichlorophenoxyacetic acid

j4-(2-(4-(hexyloxy)phenyl)propan2-yl)phenol

${ }^{\mathrm{k}} \operatorname{Poly}(2,5-b i s(3-t e t r a d e c y l t h i o p h e n-2-y l)$ thieno[3,2-b]thiophene)

${ }^{1} \mathrm{C}$-reactive protein

${ }^{\mathrm{m}}$ Myelin basic protein

${ }^{\mathrm{n}}$ Polystyrene-co-methacrylic acid

${ }^{\mathrm{o}}$ Biotinylated phospholipids 
et al. [55] studied the hybridization mechanism under high ionic strength and deduced the principle of the adaptation of device structure design to sensing performance in another work, then optimized the layout of sensors and verified the possibility of pre-adjusting the device structure to enable a sensing function. Since the DNA molecule had a negatively charged phosphoric acid group, which introduced a positive bias between the gate and the source, the target DNA could be immobilized by electrostatic induction.

Gui et al. [56] used the known single-stranded DNA (ssDNA) molecules as target DNA sequences and fixed them onto pentacene thin films by physical adsorption to form a dsDNA (double-stranded DNA, dsDNA) sensing unit that can quickly detect unknown DNA sequences. The authors also explored the effects of hybridization temperature and time on hybridization efficiency and device sensitivity. Because the pentacene film was sensitive to the detection environment, the physical adsorption method may have a negative impact on the stability of the device. Chen et al. [57] fixed ssDNA modified with mercapto group $(-\mathrm{SH})$ on Au electrode by covalent bonding, and distinguished ssDNA and dsDNA according to the change in the contact resistance, which reduced the possibility of damage to the active layer.

Shi et al. [58] demonstrated that an OFET with high mobility could be prepared by inserting water-soluble DNA between the source-drain electrode and a pentacene film by a spray-coating process. In a subsequent study, the researchers demonstrated that direct spray coating of DNA molecules [59] or the thermal deposition of guanine [60] as the sensing layer between the dielectric layer and pentacene could greatly improve the sensitivity of $\mathrm{NO}_{2}$ detection. Park et al. [61] discussed the mechanism of DNA label-free detection using pentacene thin-film transistors with a gold floatinggate electrode in the active layer (Fig. 9a). To do so, thiolated ssDNA polynucleotide probes were immobilized on a gold floating-gate electrode by chemical bonding. Using this device, the target gene of a lambda phage virus DNA was captured and detected, and the working principle of the floating-electrode pentacene thin-film transistor sensor was investigated. As the work function increased, the authors found the Schottky barrier of the device to be enhanced and a charge screening effect was produced. The negative charge carried by DNA caused a positive shift in the threshold voltage.

Since unmodified pentacene lacks tunability, DNA can only be immobilized by physical adsorption. Lee et al. [62] developed a functionalized graphene oxide (GO) ink. With the help of inkjet-printing technology, a GO support system (GOSS) formed $\pi-\pi$ bonds with the aromatic rings of pentacene to then form a stable sensing layer (Fig. 9b).The combination of functionalized GO ink with a DNA probe or antibody was the key to detection. First, the authors functionalized bare GO nanosheets with carboxylic acid to obtain GO-COOH. After blocking amine active groups on the GO by triethylamine, GO-PEG- $\mathrm{NH}_{2}$ was synthesized from 6-arm-PEG-amine by coupling carboxyl groups with EDC. Sulfo-SMCC treatment was then performed to obtain sulfhydryl-activated GO, which can be used as an anchoring agent for thiolated DNA and a half antibody by the Michael addition reaction. A GOSS with a maleimide group could be used to form a network structure on the surface of pentacene to provide binding sites for ssDNA or human epidermal growth factor receptor 2 (HER2) without changing the device, thereby enabling versatility in biomolecular detection (Fig. 9d).

In Fig. 9, we can see that Park et al. utilized an additional floating electrode to protect the active layer and achieve better alignment and target-specific detection. In the future, lower detection limits can be realized. The GOSS designed by Lee et al. can be easily synthesized in bulk to independently obtain the selected sensing layer. By integration with different sensors and the combination of different probes, the universal detection of DNA or CTCs is realized. In future research, this biosensor will be combined with integrated circuits to demonstrate a wireless medical point sensor. Table 3 shows a summary of the modified interface and methods that use DNA.

\section{Conclusions}

Based on the principles of biocompatibility, selectivity, sensitivity, and stability, in this review, we summarized and evaluated strategies for integrating enzymes, Abs, aptamers, and DNA molecules in OFET biosensors. OFET biosensors can improve sensing performance by optimizing the device structure or developing new biocompatible, stable OSC, or sensing-layer materials. When biological or chemical sensing is achieved in complex media, further expansion is possible of applications in clinical medicine and other fields. At present, although OFET's inherent signal transduction and signal amplification functions have led to the remarkable development of OFET-based biosensors, considerable challenges remain. We believe that the following issues must be addressed: (1) the development of new molecular design strategies and biomolecular grafting methods for OSC with functional groups; (2) in-depth study of the influence of analytes or stimuli on the charge behavior in the conductive channel; (3) achieving a balance of the original performance of a device with improved sensing capabilities; and (4) derivation of the principles of adaptive device structure design to enable tailoring with respect to specific sensing needs. We must fully understand the relationship between sensing performances and device structure to pre-adjust the device structure for fixation and sensing based on the characteristics 
(a)

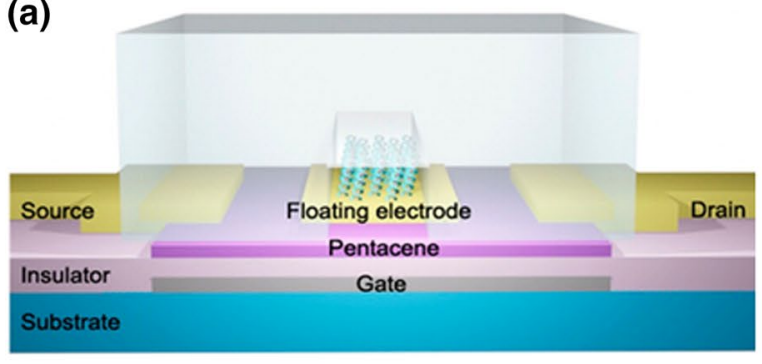

(b)

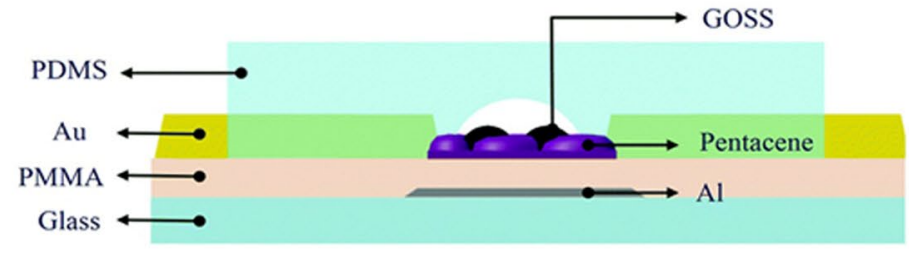

(c)

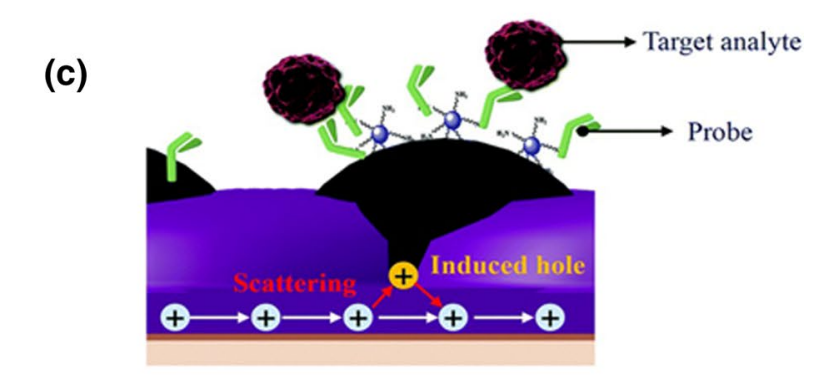

(d)
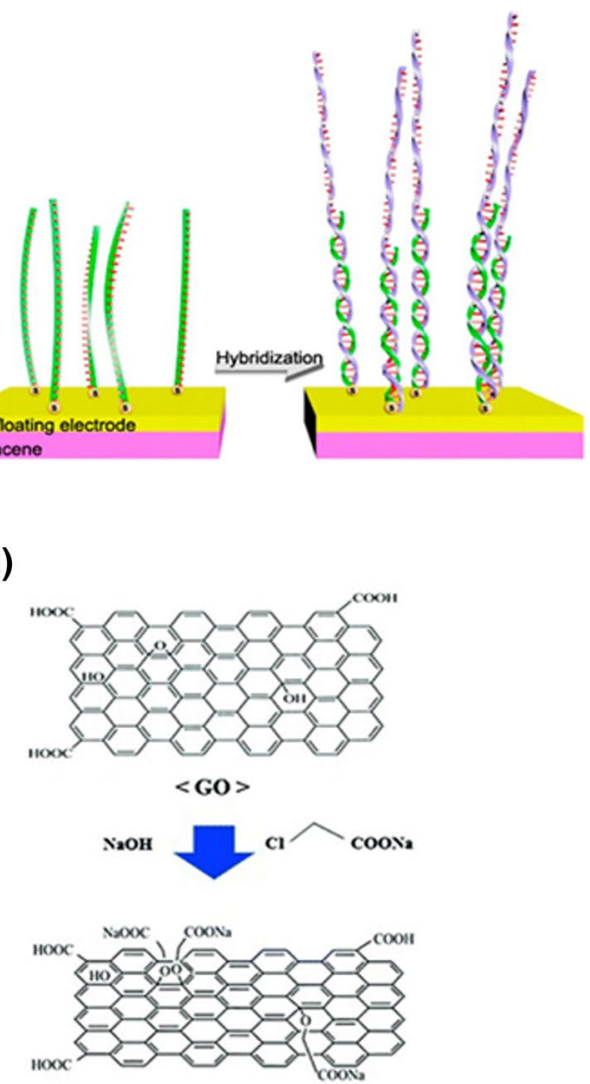

Gold floating electrode Pentacene
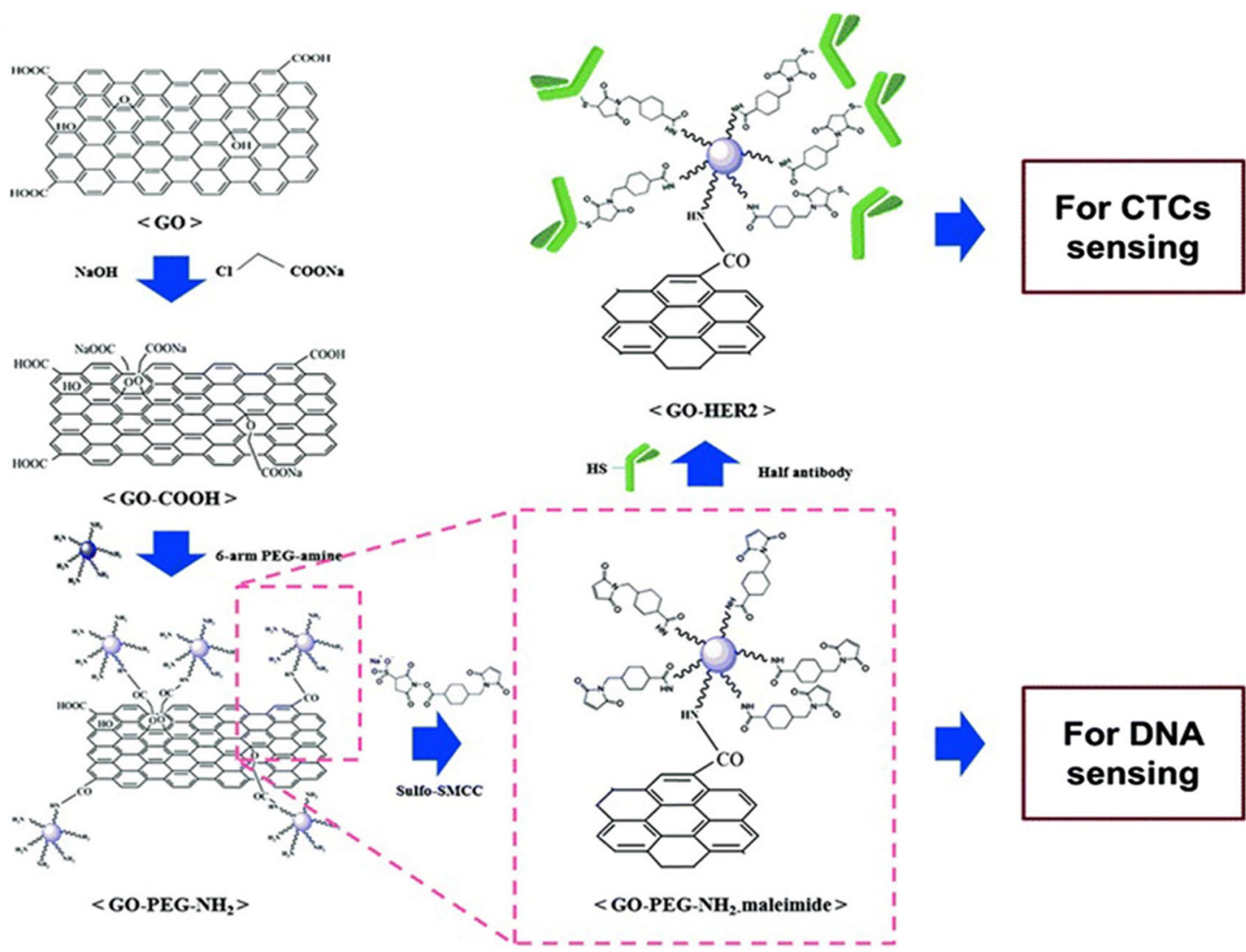

Hs -2 Half antibody

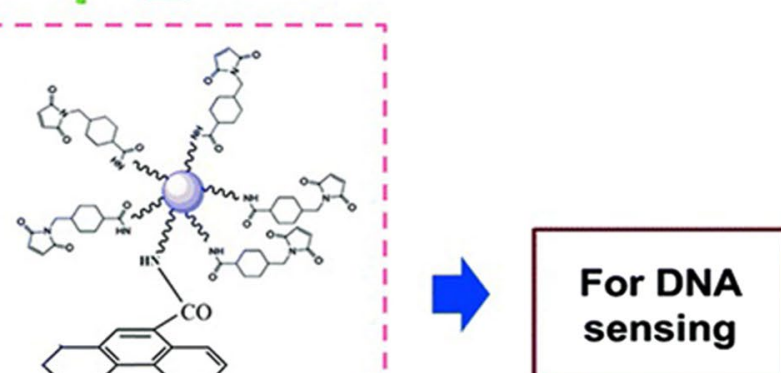

Fig. 9 Schematic of microchannel integrated pentacene TFT with Au floating electrode. a Cross-sectional scheme of TFT and immobilization of thiolated DNA probe and hybridization with target DNA on Au floating electrode (reprinted from [61] with permission from ACS). Schematic of the $\mathbf{b}$ cross-sectional structure, $\mathbf{c}$ sensing mecha-

nism of a microchannel integrated GOSS-pentacene FET biosensor and $\mathbf{d}$ synthetic scheme for the fabrication of GO complexes (GOPEG-NH2 and GO-HER2) (reprinted from [62] with permission from RSC) 
Table 3 Summary of methods based on fixed DNA

\begin{tabular}{lllll}
\hline Modified interface & Immobilization molecule & Detection substance & Immobilization method & References \\
\hline a S-D electrode & bssNA & Unknown DNA & S-Au & Spray coating \\
S-D/pentacene & Water-soluble DNA & - & Spray coating & [57] \\
Dielectric/OSC & DNA & $\mathrm{NO}_{2}$ & thermal deposition & {$[58]$} \\
& Guanine & $\mathrm{NO}_{2}$ & $\mathrm{~S}-\mathrm{Au}$ & {$[60]$} \\
Floating electrode & Thiolated ssDNA & Lambda phage virus DNA & Physical adsorption & {$[61]$} \\
Pentacene & ssDNA & Unknown DNA & Inkjet printing & {$[56]$} \\
& GO-PEG-NH & DNA & ${ }^{c}$ CTCs & Inkjet printing \\
\hline
\end{tabular}

${ }^{\text {a }}$ Source-drain gold electrode

${ }^{\text {b }}$ Single-stranded DNA

${ }^{\mathrm{c}}$ Circulating tumor cells

of the biomolecules. The key and major difficulty in further improving the sensitivity and stability of OFET devices is to fix biological molecules according to a suitable strategy to ensure their activity while maximizing molecular recognition and minimizing device damage. In addition, the high-level integration of equipment is a clear trend in future development.

Acknowledgements This study was supported by the National Natural Science Foundation of China (Nos. 21922409, 21976131, 21575100) and Tianjin Research Program of Application Foundation and Advanced Technology (Nos. 18JCZDJC37500, 17JCYBJC20500).

Open Access This article is licensed under a Creative Commons Attribution 4.0 International License, which permits use, sharing, adaptation, distribution and reproduction in any medium or format, as long as you give appropriate credit to the original author(s) and the source, provide a link to the Creative Commons licence, and indicate if changes were made. The images or other third party material in this article are included in the article's Creative Commons licence, unless indicated otherwise in a credit line to the material. If material is not included in the article's Creative Commons licence and your intended use is not permitted by statutory regulation or exceeds the permitted use, you will need to obtain permission directly from the copyright holder. To view a copy of this licence, visit http://creativecommons.org/licenses/by/4.0/.

\section{References}

1. Li H, Shi W, Song J et al (2019) Chemical and biomolecule sensing with organic field-effect transistors. Chem Rev 119(1):3-35

2. Han ST, Peng HY, Sun QJ et al (2017) An overview of the development of flexible sensors. Adv Mater 29(33):1700375

3. Park J, Kim M (2015) Strategies in protein immobilization on a gold surface. Appl Sci Converg Technol 24(1):1-8

4. Choi J, Jeon HG, Kwon OE et al (2015) Improved output characteristics of organic thin film transistors by using an insulator/protein overlayer and their applications. J Mater Chem C 3(11):2603-2613

5. Li XL, Shi W, Yu XG et al (2015) Performance improvement of organic field-effect transistor based nitrogen dioxide gas sensor using biocompatible PMMA/silk fibroin bilayer dielectric. J Mater Sci: Mater Electron 26(10):7948-7954

6. Lee JH, Kwak HW, Park MH et al (2018) Understanding hydroscopic properties of silk fibroin and its use as a gate-dielectric in organic field-effect transistors. Org Electron 59:213-219

7. Park MH, Kim J, Lee SC et al (2016) Critical role of silk fibroin secondary structure on the dielectric performances of organic thin-film transistors. RSC Adv 6(7):5907-5914

8. Liang FC, Huang YH, Kuo CC et al (2018) Thermally deposited silk fibroin as the gate dielectric layer in organic thin-film transistors based on conjugated polymer. React Funct Polym 131:368-377

9. Singh R, Lin YT, Chuang WL et al (2017) A new biodegradable gate dielectric material based on keratin protein for organic thin film transistors. Org Electron 44:198-209

10. Picca RA, Manoli K, Luciano A et al (2018) Enhanced stability of organic field-effect transistor biosensors bearing electrosynthesized $\mathrm{ZnO}$ nanoparticles. Sensor Actuat B Chem 274:210-217

11. Zhang WH, Jiang BJ, Yang P (2016) Proteins as functional interlayer in organic field-effect transistor. Chin Chem Lett 27(8):1339-1344

12. Sportelli MC, Picca RA, Manoli K et al (2017) Surface analytical characterization of streptavidin/poly(3-hexylthiophene) bilayers for bio-electronic applications. Appl Surf Sci 420:313-322

13. Leonardi F, Casalini S, Albonetti C et al (2015) Charge-injection organic gauges to detect dopamine down to the nanomolar scale. IEEE Trans Electron Dev 62(12):4251-4257

14. Oh J, Lee JS, Jun J et al (2017) Ultrasensitive and selective organic FET-type nonenzymatic dopamine sensor based on platinum nanoparticles-decorated reduced graphene oxide. ACS Appl Mater Interfaces 9(45):39526-39533

15. Zhang Y, Li J, Li R et al (2017) Liquid-solid dual-gate organic transistors with tunable threshold voltage for cell sensing. ACS Appl Mater Interfaces 9(44):38687-38694

16. Spanu A, Lai S, Cosseddu P et al (2015) An organic transistorbased system for reference-less electrophysiological monitoring of excitable cells. Sci Rep 5:8807

17. Spanu A, Tedesco MT, Martines L et al (2018) An organic neurophysiological tool for neuronal metabolic activity monitoring. APL Bioeng 2(4):046105

18. Mulla MY, Tuccori E, Magliulo M et al (2015) Capacitance-modulated transistor detects odorant binding protein chiral interactions. Nat Commun 6:6010

19. MacChia E, Alberga D, Manoli K et al (2016) Organic bioelectronics probing conformational changes in surface confined proteins. Sci Rep 6:28085 
20. Minami T, Sato T, Minamiki T et al (2015) A novel OFET-based biosensor for the selective and sensitive detection of lactate levels. Biosens Bioelectron 74:45-48

21. Minamiki T, Tokito S, Minami T (2019) Fabrication of a flexible biosensor based on an organic field-effect transistor for lactate detection. Anal Sci 35(1):103-106

22. Minami T, Sato T, Minamiki T et al (2015) An extended-gate type organic FET based biosensor for detecting biogenic amines in aqueous solution. Anal Sci 31(7):721-724

23. Minami T, Sasaki Y, Minamiki T et al (2016) Selective nitrate detection by an enzymatic sensor based on an extended-gate type organic field-effect transistor. Biosens Bioelectron 81:87-91

24. Werkmeister FX, Koide T, Nickel BA (2016) Ammonia sensing for enzymatic urea detection using organic field effect transistors and a semipermeable membrane. J Mater Chem B 4(1):162-168

25. Furusawa H, Ichimura Y, Nagamine K et al (2018) Detection of 1,5-anhydroglucitol as a biomarker for diabetes using an organic field-effect transistor-based biosensor. Technologies 6(3):77

26. Krajewska B (2004) Application of chitin- and chitosan-based materials for enzyme immobilizations: a review. Enzym Microb Technol 35(2-3):126-139

27. Mano T, Nagamine K, Ichimura $Y$ et al (2018) Printed organic transistor-based enzyme sensor for continuous glucose monitoring in wearable healthcare applications. ChemElectroChem 5(24):3881-3886

28. Elkington D, Wasson M, Belcher $\mathrm{W}$ et al (2015) Printable organic thin film transistors for glucose detection incorporating inkjetprinting of the enzyme recognition element. Appl Phys Lett 106(26):263301

29. D'Ayala G, Malinconico M, Laurienzo P (2008) Marine derived polysaccharides for biomedical applications: chemical modification approaches. Molecules 13(9):2069-2106

30. Dumitru LM, Manoli K, Magliulo M et al (2015) A hydrogel capsule as gate dielectric in flexible organic field-effect transistors. APL Mater 3(1):014904

31. Shen HG, Zou Y, Zang YP et al (2018) Molecular antenna tailored organic thin-film transistors for sensing application. Mater Horiz 5(2):240-247

32. Jung Y, Jeong JY, Chung BH (2008) Recent advances in immobilization methods of antibodies on solid supports. Analyst 133(6):697

33. Ravi Shankaran D, Miura N (2007) Trends in interfacial design for surface plasmon resonance based immunoassays. J Phys D Appl Phys 40(23):7187-7200

34. Minamiki T, Minami T, Sasaki Y et al (2015) An organic fieldeffect transistor with an extended-gate electrode capable of detecting human immunoglobulin A. Anal Sci 31(7):725-728

35. Fukuda K, Minamiki T, Minami T et al (2015) Printed organic transistors with uniform electrical performance and their application to amplifiers in biosensors. Adv Electron Mater 1(7):1400052

36. Minamiki T, Minami T, Sasaki Y et al (2016) Label-free detection of human glycoprotein (CgA) using an extended-gated organic transistor-based immunosensor. Sensors 16(12):2033

37. Sam S, Touahir L, Salvador Andresa J et al (2010) Semiquantitative study of the EDC/NHS activation of acid terminal groups at modified porous silicon surfaces. Langmuir 26(2):809-814

38. Ji XD, Zhou PC, Zhong L et al (2018) Smart surgical catheter for $\mathrm{C}$-reactive protein sensing based on an imperceptible organic transistor. Adv Sci 5(6):1701053

39. Casalini S, Dumitru AC, Leonardi F et al (2015) Multiscale sensing of antibody-antigen interactions by organic transistors and single-molecule force spectroscopy. ACS Nano 9(5):5051-5062
40. Lee JE, Seo JH, Kim CS et al (2013) A comparative study on antibody immobilization strategies onto solid surface. Kor J Chem Eng 30(10):1934-1938

41. Berto M, Vecchi E, Baiamonte L et al (2019) Label free detection of plant viruses with organic transistor biosensors. Sens Actuators B Chem 281:150-156

42. Głowacki ED, Tangorra RR, Coskun H et al (2015) Bioconjugation of hydrogen-bonded organic semiconductors with functional proteins. J Mater Chem C 3(25):6554-6564

43. Piro B, Wang DJ, Benaoudia D et al (2017) Versatile transduction scheme based on electrolyte-gated organic field-effect transistor used as immunoassay readout system. Biosens Bioelectron 92:215-220

44. Nguyen TTK, Nguyen TN, Anquetin G et al (2018) Triggering the electrolyte-gated organic field-effect transistor output characteristics through gate functionalization using diazonium chemistry: application to biodetection of 2, 4-dichlorophenoxyacetic acid. Biosens Bioelectron 113:32-38

45. Magliulo M, de Tullio D, Vikholm-Lundin I et al (2016) Labelfree C-reactive protein electronic detection with an electrolytegated organic field-effect transistor-based immunosensor. Anal Bioanal Chem 408(15):3943-3952

46. Seshadri P, Manoli K, Schneiderhan-Marra N et al (2018) Lowpicomolar, label-free procalcitonin analytical detection with an electrolyte-gated organic field-effect transistor based electronic immunosensor. Biosens Bioelectron 104:113-119

47. Song J, Dailey J, Li H et al (2018) Influence of bioreceptor layer structure on myelin basic protein detection using organic field effect transistor-based biosensors. Adv Funct Mater 28(37): 1802605

48. Mulla MY, Seshadri P, Torsi L et al (2015) UV crosslinked poly(acrylic acid): a simple method to bio-functionalize electrolyte-gated OFET biosensors. J Mater Chem B 3(25):5049-5057

49. Palazzo G, de Tullio D, Magliulo M et al (2015) Detection beyond Debye's length with an electrolyte-gated organic field-effect transistor. Adv Mater 27(5):911-916

50. Song J, Dailey J, Li H et al (2017) Extended solution gate OFETbased biosensor for label-free glial fibrillary acidic protein detection with polyethylene glycol-containing bioreceptor layer. Adv Funct Mater 27(20):1606506

51. Diacci C, Berto M, di Lauro M et al (2017) Label-free detection of interleukin- 6 using electrolyte gated organic field effect transistors. Biointerphases 12(5):05F401

52. Berto M, Casalini S, di Lauro M et al (2016) Biorecognition in organic field effect transistors biosensors: the role of the density of states of the organic semiconductor. Anal Chem 88(24):12330-12338

53. Berto M, Diacci C, D'Agata R et al (2018) EGOFET peptide aptasensor for label-free detection of inflammatory cytokines in complex fluids. Adv Biosyst 2(2):1700072

54. de Oliveira RF, Merces L, Vello TP et al (2016) Water-gated phthalocyanine transistors: operation and transduction of the peptideenzyme interaction. Org Electron 31:217-226

55. Lai S, Barbaro M, Bonfiglio A (2016) Tailoring the sensing performances of an OFET-based biosensor. Sens Actuators B Chem 233:314-319

56. Gui HY, Wei B, Wang J (2015) The hybridization and optimization of complementary DNA molecules on organic field-effect transistors. Mater Sci Semicond Process 30:250-254

57. Chen X, Gui HY, Wei B et al (2015) A label-free biosensor based on organic transistors by using the interaction of mercapto DNA and gold electrodes. Mater Sci Semicond Process 35:127-131

58. Shi W, Han SJ, Huang W et al (2015) High mobility organic fieldeffect transistor based on water-soluble deoxyribonucleic acid via spray coating. Appl Phys Lett 106(4):043303 
59. Shi W, Yu XG, Zheng YF et al (2016) DNA based chemical sensor for the detection of nitrogen dioxide enabled by organic fieldeffect transistor. Sens Actuators B Chem 222:1003-1011

60. Shi W, Yu J, Katz HE (2018) Sensitive and selective pentaceneguanine field-effect transistor sensing of nitrogen dioxide and interferent vapor analytes. Sens Actuators B Chem 254:940-948

61. Park MH, Han D, Chand R et al (2016) Mechanism of label-free DNA detection using the floating electrode on pentacene thin film transistor. J Phys Chem C 120(9):4854-4859

62. Lee DH, Cho HS, Han D et al (2017) Highly selective organic transistor biosensor with inkjet printed graphene oxide support system. J Mater Chem B 5(19):3580-3585

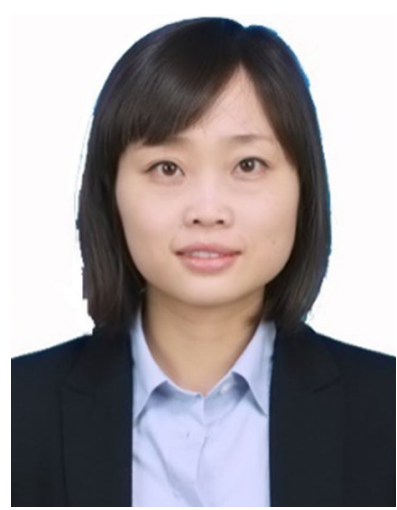

Yin Xiao graduated from Tianjin University with a dual bachelor degree in Chemical Engineering and Technology and Applied Mathematics in 2004. She received her M.S. (2007) in applied chemistry form Tianjin University and Ph.D. (2011) in chemical and biomedical engineering from Nanyang Technological University, Singapore. She joined Tianjin University in 2012 and now is an associate professor in School of Chemical
Engineering and Technology, Tianjin University. Her research interests focus on the organic semiconducting materials and devices.

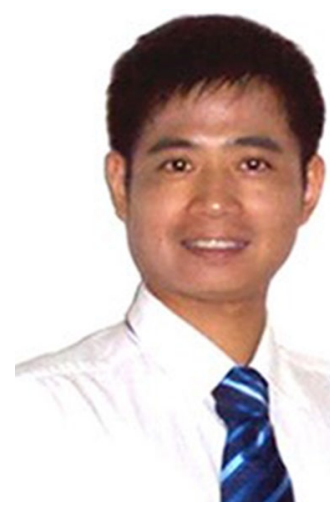

Yong Wang received his Ph.D. degree from Singapore Nanyang Technological University (NTU) in 2011, master degree in 2007 , and dual bachelor degree in 2004 from Tianjin University (TJU). He worked as a research fellow in NTU from January to December in 2011 and joined TJU in early 2012 as an associated professor. In late 2015 , he was promoted to the full professor and assigned as the associate director of chemistry department. From March 2017 to February 2019, he worked in National Natural

Science Foundation of China as a project manager. Now he is the associate dean of School of Science in charge of graduate students and research. His research interests include high resolution chiral separation and sensing. 